\title{
Cuestiones especiales de operación del sistema interamericano de protección de los derechos humanos ${ }^{1}$
}

\author{
Por Antônio Augusto Cançado Trindade
}

Los más diversos experimentos contemporáneos de supervisión internacional, llevados a cabo por organizaciones internacionales, han desarrollado, en los últinos años, sofisticados y eficaces mecanismos de control de su cumplimiento (e.g., informes periódicos, procedimientos de interpretación de acuerdos intemacionales, reclamaciones o demandas de diversas modalidades). 2 La experiencia histórica del sistema interamericano de protección de los derechos humanos hasta el presente ha demostrado que, en efecto, es posible fortalecer la posición de los particulares en el plano internacional por medio de instrumentos de protección de sus derechos con base, contenido e efectos jurídicos distintos.

En nuestros dias, dos cuestiones especiales de operación del sistema regional de protección merecen particular atención: la del agotamiento de los recursos intemos, y la de la relación y coordinación del derecho de petición o comunicación en el presente sistema regional con otros procedimientos intemacionales. La primera se plantea en una dimensión "vertical" (de la interacción entre el derecho intemacional y el derecho interno), la segunda en una dimensión "horizontal" (situándose en el plano propio del derecho internacional). A partir de la actuación de la Comisión Interamericana y, en menor escala hasta hoy, de la actuación de la Corte Interamericana, pasemos de inicio al examen de la evolución de la aplicación por estos órganos de la regla del previo agotamiento de los recursos del derecho intemo.

\section{La Aplicación de la Regla del Agotamiento de los Recursos Internos}

Como se sabe, estamos delante de la regla de derecho internacional en virtud de la cual se debe dar al Estado la oportunidad de reparar un supuesto daño en el ámbito de su propio ordenamiento jurídico interno, antes de que se pueda invocar su responsabilidad intemacio-

1 Trabajo de investigación que sirvió de base para las conferencias pronunciadas por el Autor, originalmente en el Vigesimo Curso Exterior de la Academia de Derecho Intemacional de la Haya (Bogotá, junio de 1989), y, en versión actualizada, en las Jomadas del Consejo Argentino para las Relaciones Intemacionales y del Comité Intemacional de la Cruz Roja (Buenos Aires, agosto de 1990).

2 L. B. Sohn, "Procedures Developed by Intemational Organizations for Checking Compliance", The Effectiveness of International Decisions (ed. S. Schwebel), Leiden, Sijthoff/Oceana, 1971, pp. 5156. 
nal; es una de las cuestiones que con mayor frecuencia se suscitan en el contencioso international relativo tanto a la protección diplomática de nacionales en el exterior, como a la protección diplomática de nacionales en el exterior, como a la protección internacional de los derechos humanos. La práctica de la Comisión Interamericana sobre la admisibilidad de peticiones referentes a las violaciones de derechos humanos ha llamado relativamente poco la atención de los especialistas, hasta el momento, si se compara con la amplia bibliografía especializada sobre la práctica correspondiente de la Comisión Europea. En ambos contextos regionales, una de las condiciones de admisibilidad que con mayor frecuencia y eficacia se presenta, es precisamente la del previo agotamiento de los recursos internos. En el ámbito institucional del sistema interamericano de protección de los derechos humanos, la contribución de la práctica de la Comisión Interamericana sobre todo, en cuanto a esta condición de admisibilidad de peticiones internacionales, no debería pasar desapercibida.

Para los familiarizados con la jurisprudencia de la Comisión Europea, tal vez el primer rasgo marcante de la práctica de la Comisión Interamericana - a la luz de las disposiciones pertinentes 3 - sobre la cuestión de agotamiento de los recursos intemos sea la diversidad de enfoques y soluciones dados al problema, conforme se puede verificar del análisis de la práctica de la Comisión Interamericana sobre el matéria. La Comisión ejerce - a lo que debería darsele énfasis en esa etapa preliminar - una función bastante importante durante el proceso: después de examinar si las condiciones de admisibilidad fueron debidamente cumplidas en cada caso concreto, la Comisión reúne las peticiones (las que sobrevivieron a la etapa de admisibilidad) según las violaciones de derechos humanos de que se quejan, estableciendo de esta manera el estado de observancia de cada uno de los derechos protegidos en los países en cuestión. Por consiguiente, dificilmente se podría tener estrictamente como "parte" al individuo reclamante en un caso; al contrario, todo el procedimiento desarrolla directamente entre la propia Comisión Interamericana y el Estado reclamado.

3 Cf., antes de la resolución 447 de 1979: artículo 9 (bis) (d) del Estatuto de la Comisión, y artículo 54 del Reglamento de la Comisión. Y, actualmente: artículos 46 (1) (a) y (2) (a, b, c) y 47 de la Convención Americana sobre Derechos Humanos; artículos 19 (a) y 20 (c) del nuevo Estatuto (aprobado en 1980) de la Comisión; y artículo 34 del nuevo Reglamento (aprobado en 1980) de la Comisión. 
1. El Agotamiento de los Recursos Internos en la Práctica de la Comisión Interamericana de Derechos Humanos

En algunos casos 4 la constatación del no-agotamiento de los recursos internos por los reclamantes ha ocasionado, simplemente, el rechazo de las peticiones por la Comisión Interamericana como inadmisibles por esta razón. En otras ocasiones 5 , la Comisión, sin hacer mención expresa a la "inadmisibilidad", decidió que, como no habían sido agotados los recursos internos, no se tomaría ninguna otra medida en los casos en cuestión y las peticiones serian archivadas y la decisión comunicada a los reclamantes. miento

Los casos de inadmisibilidad pura y simple, por no-agotamiento, no han sido, sin embargo, los más numerosos en la práctica de la Comisión. En efecto, en los casos en que la Comisión verificó, en determinado momento, que los recursos internos no habían sido agotados, decidióaplazar la continuación del examen de la cuestión exactamente por este motivo6, algunas veces precisando el recurso que debía ser agotado. ${ }^{7}$ En tales casos la Comision parece haber aplicado la regla de los recursos internos con notable flexibilidad: en lugar de declarar las peticiones inadmisibles inmediatamente por no-agotamiento de los recursos intemos, prefirió postergar el estudio más a fondo de los casos hasta que los reclamantes hubiesen agotado los recursos intemos dentro de un plazo razonable. Al aplicar de esta

4 Casos n⿳9. 1569 y 1578 (conjuntamente), Inter-American Commission on Human Rights (IACHR), Report on the Work. Accomplished during Its Twentieth Session - 1968 (en adelante abreviado Report - Session), pp. 13-14; caso $\mathrm{n}^{\circ} 1625$, IACHR, Report 24th Session - 1970, p. 16; caso $\mathrm{n}^{\circ}$ 1575, IACHR, Report 21st Session - 1969, pp. 22-23; caso ne 1671, IACHR, Report 24th Session 1970, pp. 20-22; caso $n^{9} 1579$, IACHR, Report 20th Session - 1968, pp. 22-23; caso $n^{2} 1744$, IACHR, Report 31st Session - 1973, p. 61, e cf. Comisión Interamericana de Derechos Humanos (CIDH), Relatório 30a. Sessao - 1973, p. 64; caso n 1752, IACHR, Report 31st Session - 1973, p. 44; caso n 1740, CIDH, Informe Anual Correspondiente a 1973, p. 103, y cfl. CIDH, Relatório 30a. Sessao - 1973, p. 19; caso n¹773, CIDH, Informe Anual Correspondiente a 1974, p. 76.

5 Caso $n^{9}$ 1628, IACHR, Report 23rd Session - 1970, p. 11; caso $\mathrm{n}^{2} 1704$, IACHR, Report 25th Session - 1971, p. 18; caso $n^{2} 1725$, IACHR, Report 26th Session - 1971, pp. 15-16; caso $n^{2} 1731$, IACHR, Report 27th Session - 1972, p. 10.

6 Caso $n^{9} 1586$, IACHR, Report 19th Session - 1968, p. 10; caso $n^{2} 1679$, IACHR, Report 24th Session - 1970, p. 16; casos $n^{2}$ s. 1680 e 1682, IACHR, Repor 24th Session - 1970, p. 16; caso $n^{9}$ 1689, IACHR, Report 25th Session - 1971, pp. 30-31; caso $\mathrm{n}^{\mathrm{Q}}$ 1673, IACHR, Report 23rd Session 1970, p. 10; caso $n^{9} 1681$, IACHR, Repon 24th Session - 1970, p. 16; caso $n^{2} 1735$, IACHR, Report 31 st Session - 1973, p. 41.

7 E.g., caso $\mathrm{n}^{\mathrm{2}}$ 1738, IACHR, Report 31 st Session - 1973, p. 42 (recurso de amparo, pendiente). 
manera la regla de los recursos internos, la Comisión de cierto modo benefició a los reclamantes. Por otro lado, en otros casos, sin embargo, el aplazamiento de la decisión parece haber beneficiado a los gobiemos reclamados, al extenderles el plazo - supuestamente para una consideración en cuanto a la reparación, a nivel nacional, de los supuestos daños. 8 En otros casos 9 , las razones del aplazamiento no fueron suficientemente claras.

\section{c) Solicitud de Informaciones Adicionales sobre el Agotamiento}

Tal vez el mayor número de decisiones tomadas por la Comisión Interamericana en relación con la aplicación de la regla de los recursos intemos haya asumido la forma de solicitudes de informaciones adicionales concernientes al agotamiento, con el fin de facilitarle a la Comisión tomar subsiguientemente una decisión definitiva sobre la materia. En primer lugar, solicitudes de informaciones, dirigidas a los propios gobiemos reclamados, acerca de los recursos intemos a ser agotados. 10 En uno de esos casos esta actitud de la Comisión condujo a un resultado sorprendente: la Comisión había solicitado reiteradamente al gobierno reclamado informaciones relativas al agotamiento de los recursos internos, pero como no fué atendida en sus solicitudes y tampoco el reclamante actualizó su petición, la Comisión decidió archivar el caso "sin perjuicio de retomar su examen si las informaciones fueren suministradas en un plazo razonable", una vez que en aquella etapa sentía que no poseía informaciones suficientes para tomar una decisión sobre el casol1 (cf. infra). Sin embargo, es difícil evitar la impresión de que el gobiemo reclamado sea indebidamente favorecido por esta manera de aplicar la regla de los recursos internos. Si un gobiemo reclamado no aprovecha la oportunidad de presentar la objeción de no-agotamiento y de

8 Caso $n^{9}$ 1683, IACHR, Report 26th Session - 1971, pp. 19-22, y Report 27th Session - 1972, pp. 20-24; caso $\mathrm{n}^{2}$ 1684, IACHR, Report 26th Session - 1971, pp. $22-25$.

9 Caso $n^{9}$ 1705, IACHR, Report 27th Session - 1972, pp. 35-38, y Report 28th Session - 1972, pp. 29-31; caso $n^{9} 1697$, IACHR, Report 27th Session - 1972, pp. 24-27, y Report 28th Session - 1972, pp. 8-13.

10 Caso $\mathrm{n}^{2}$ 1631, IACHR, Report 24th Session - 1970, pp. 29-33, y Report 25th Session - 1971, pp. 37-38; caso no 1693, IACHR, Report 26th Session - 1971, pp. 30-31; caso $n^{2} 1748$, IACHR, Report 29th Session - 1972, pp. 13-14; caso $n^{2} 1683$, in ibid., p. 25; caso $n^{2} 1684$, in ibid., pp. 25-26; caso $\mathrm{n}^{2} 1690$, in ibid.,pp. 26-28; caso $\mathrm{n}^{2} 1755$, IACHR, Report 31st Session - 1973, p. 53, y CIDH, Relatório 30a. Sessao - 1973, p. 52 (pedido de informaciones sobre recursos de habeas corpus); caso $\mathrm{n}^{2} 1769$, in ibid., pp. 20-21; caso $\mathrm{n}^{\mathrm{Q}} 1735$, IACHR, Report 32nd Session - 1974, p. 29; caso $\mathrm{n}^{\mathrm{Q}}$ 1774, CIDH, Informe Anual Correspondiente a 1974, pp. 52-56; caso $\mathrm{n}^{\mathrm{Q}} 1810$, in ibid., o. 67; caso $\mathrm{n}^{2} 1810$, in ibid., p. 67; caso $\mathrm{n}^{2} 1752$, in ibid., pp. 69-70; caso $n^{2} 1773$, in ibid., pp. 70-71 y 73-75; cason $^{2}$ 1788, CIDH, Informe Anual Correspondiente a 1975, pp. 80-81; cason ${ }^{2} 1844$, in ibid., pp. 84-85; caso $\mathrm{n}^{9} 1897$, in ibid., pp. 86-87; caso $\mathrm{n}^{9} 1840$, in ibid., p. 103; caso $\mathrm{n}^{9} 1799$, in ibid., p. 104; caso $n^{2} 1840$, in ibid., pp. 110-111; caso $n^{\circ} 1845$, in ibid., p. 112; caso $n^{\circ} 1849$, in ibid., p. 114; caso $^{2} 2711$, CIDH, Informe Anual - 1982-1983, p. 139.

11 Cason $^{2} 1631$, IACHR, Report 25th Session - 1970, pp. 37-38. 
fundamentarla, no hay aparentemente razón alguna para que la Comisión no deba decidir a favor del reclamante.

En segundo lugar, en otras ocasiones la Comisión solicitó a los reclamantes informaciones adicionales acerca de las medidas tomadas para agotar los recursos intemos. $12 \mathrm{Y}$ en tercer lugar, la Comisión solicitó - en la mayoría de tales casos - informaciones adicionales sobre el agotamiento de los recursos internos, tanto a los individuos reclamantes como a los gobiemos reclamados. 13 Los recursos intemos que deben ser agotados varian de caso a caso, desde, v.gr., recursos establecidos por un decreto-ley 14 hasta un recurso de amparo pendiente. 15 En un determinado caso la cuestión del agotamiento de un recurso (apelación) se complicó por alegaciones de atrasos indebidos en la administración de justicia; en consecuencia, la Comisión decidió mantener el caso pendiente.16 En otra ocasión, como los reclamantes no fundamentaron sus quejas, la Comisión decidió archivar el caso.17 En varios otros casos, estando pendiente la obtención de informaciones más detallades, la

12 Caso $n^{2}$ 1621, IACHR, Repon 21st Session - 1969, p. 16; caso $n^{2} 1461$, IACHR, Report 22nd Session - 1969, p. 35; caso $n^{2} 1751$, IACHR, Report 29th Session - 1972, p. 15; caso $n^{2} 1754$, IACHR, Report 29th Session - 1972, p. 18; caso $n^{2} 1751$, IACHR, Report 31st Session - 1973, p. 43; caso $n^{2} 1789, C I D H$, Informe Anual Correspondiente a 1974, p. 42; caso $n^{2} 1777, \mathrm{CIDH}$, Informa Anual Correspondiente a 1975, p. 91.

13 Caso $n^{9} 1620$, IACHR, Repon 21st Session - 1969, pp. 15-16; caso $n^{9} 1615$, in ibid., pp. 20-21, y Report 22nd Session - 1969, p. 35; caso $n^{2} 1641$, IACHR, Repor 24th Session - 1970, pp. 24-26; caso $n^{2} 1700$, IACHR, Report 25th Session - 1971, pp. 16-17; caso $n^{2} 1705$, in ibid., pp. 18-19, y Report 26th Session - 1971, pp. 31-32; caso $n^{2} 1723$, IACHR, Report 26th Session - 1971, p. 15; caso $n^{2} 1701$, in ibid., pp. 17-19, y Report 27tj Session - 1972, pp. 13-15; caso $n^{2} 1715$, IACHR, Report 27th Session - 1972, pp. 15-17, y Report 29th Session - 1972, pp. 19-21; caso $n^{2} 1696$, IACHR, Report 27th Session - 1972, pp. 32-34; casos n's. 1736 y 1738, IACHR, Report 29th Session - 1972, pp. 6-8; casos $\mathrm{n}^{2}$ s. 1745 y 1747, in ibid., pp. 10-12; caso $\mathrm{n}^{\mathrm{Q}} 1736, \mathrm{CIDH}$, Relatório 30a. Sessao - 1973, pp. 57-59, i IACHR, Report 31st Session - 1973, pp. 55-57, y Report 32nd Session - 1974, pp. 32-33; caso $n^{2} 1769, \mathrm{CIDH}$, Inforne Anual Correspondiente a 1974, p. 39; caso $\mathrm{n}^{9} 1736$, in ibid., p. 78. Estos casos presentaron diferencias no solamente en relación al contenido del deber de agotar los recursos intemos, pero también en relación a las medidas tomadas con posterioridad por la Comisión.

14 Caso $\mathrm{n}^{\mathrm{2}}$ 1620, IACHR, Report 21st Session-1969, pp. 15-16.

15 Caso $n^{2}$ 1738, IACHR, Report 29th Session - 1972, pp. 7-8, y CIDH, Relatório 30a. Sessao - 1973, pp. 39-40.

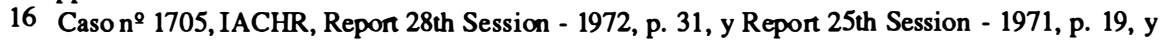
Report 26th Session - 1971, p. 31.

17 Caso ne 1615, IACHR, Repon 22nd Session - 1969, p. 35, y cf. Report 21st Session - 1969, p. 21. En cuanto a las medidas encima adoptadas por la Comisión (e.g., solicitud de informaciones adicionales $\mathrm{y}$, infra, archivamiento temporario del caso), se puede indagar si, una vez que el examen del caso es solamente postergado o su archivamiento puede todavia llevar a una investigación posterior, seria realmente necesario o conveniente a la Comisión indicar en cual estagio del proceso la regla de los recursos internos debe ser cumplica: se puede argumentar que aqui una respuesta negativa se impone. 
Comisión optó por el aplazamiento del examen de las peticiones, hasta que dispusiere de tales informaciones. 18

En uno de esos casos la Comisión, después de haber postergado la consideración de la petición hasta que fueran suministradas informaciones adicionales por el reclamado, tuvo en cuenta la respuesta del gobiemo en cuestión, en la que este "no hizo objeción alguna" en relación con el requisito del agotamiento de los recursos internos, como "habría sido normal que lo hiciera" en el caso de que estuviera pendiente una solicitud de habeas corpus u otro recurso intemo.19 En otro caso, significativamente, la Comisión consideró que cuando el gobiemo reclamado no presenta las informaciones solicitadas sobre el agotamiento de los recursos internos dentro de un plazo razonable, la observación in loco constituye un medio de verificar la aplicación de tal requisito. 20 En otra situación, si bien en poder de las informaciones presentadas por el gobiemo reclamado sobre la utilización de los recursos internos, la Comisión aún así decidió proceder a una verificación in loco.21

\section{d) Archivo de Casos sin Perjuicio de la Reapertura de Su Examen}

En los casos en que la Comisión no logró obtener pruebas actualizadas sobre la cuestión del agotamiento de los recursos intemos, decidió archivar la reclamación "sin perjuicio de reabrir su examen si las informaciones fueren suministradas dentro de un plazo razonable"22, o si informaciones adicionales sobre el tema "justificaren un nuevo estudio"23. Varios otros casos 24 fueron archivados por la Comisión sin perjuicio de reabrir la consideración de los mismos, en el evento de que se recibieren informaciones adicionales sobre el tema dentro de un plazo razonable.

18 Caso $\mathrm{n}^{\mathrm{9}} 1850, \mathrm{CIDH}$, Informe Anual Correspondiente a 1975, p. 115; caso $\mathrm{n}^{\mathrm{9}} 1809$, in ibid., p. 108; casos $n^{9}$ s. 1855 y 1857 , in ibid., pp. 118-119; caso $n^{9} 1864$, in ibid., p. 123; casos $n^{9}$ s. 1876,1877 , 1878 y 1879, in ibid., pp. 128-131; caso $n^{9} 1775$, in ibid., pp. 176-177 (en este caso, la Comisión aplazó el examen de parte de la petición, e declaró otra parte inadmisible, aunque se hubiera reconocido que los recursos intemos pertinentes fueron agotados).

19 Caso n $^{9}$ 1757, IACHR, Report 31st Session - 1973, p. 34.

20 Caso n⿳ $^{2} 1683, \mathrm{CIDH}$, Inforne Anual Correspondiente a 1973, p. 35, y cf. pp. 38 y 42.

21 Cason $^{2} 1840$, CIDH, Informe 33a. Sesión - 1974 - p. 9.

22 Caso $n^{2} 1631$, IACHR, Repor 25th Session - 1971, pp. 37-38.

23 Caso $n^{2}$ 1700, IACHR, Report 26th Session - 1971, pp. 26-27.

24 Cf. caso $n^{9} 1615$, IACHR, Report 22nd Session - 1696, p. 35; caso $n^{9} 1692$, IACHR, Report 25th Session - 1971, p. 14; caso $n^{2} 1695$, in ibid., p. 15; caso $n^{2} 1698$, in ibid., p. 16; caso $n^{2} 1712$, IACHR, Report 26th Session - 1971, pp. 7-8; casos $n^{9}$ s. 1719 y 1720, in ibid., pp. 13-14; casos $n^{9}$. 1728, 1729 y 1730, IACHR, Report 27th Session - 1972, pp. 6-9; caso $n^{9} 1733$, in ibid., pp. 11-12; caso $\mathrm{n}^{2} 1727$, in ibid., p. 35. - También han ocurrido ejemplos en que la Comisión simplemente se ha abstenido de examinar los hechos alegados en las peticiones debido al no-agotamiento de los recursos intemos: cf. caso $n^{9} 1528$, IACHR, Report 17th Session - 1967, p. 14; caso $n^{2} 1535$, in ibid., p. 14. 
En efecto, un deterininado caso que incluso había sido declarado inadmisible por noagotamiento de los recursos internos, a la luz de nuevas alegaciones de los reclamantes fue reabierto por la Comisión para examen más detallado, en clara demonstración de flexibilidad de la operación o del procedimiento de la Comisión; ésta, rápidamente, solicitó informaciones adicionales al gobierno reclamado. 25 Posteriormente, sin embargo, en poder de las informaciones solicitadas, como los reclamantes no se manifestaron sobre ellas, la Comisión decidió archivar el caso pero de nuevo sin perjuicio de la eventual reapertura de su examen en el futuro. 26

\section{e) Adopción de Resoluciones}

El examen, por la Comisión, inter alia de la cuestión del agotamiento de los recursos internos llevó, varias veces, a la medida más formal de adopción de resoluciones. 27 Esto ha occurido generalmente en casos largamente debatidos. $28 \mathrm{El}$ contenido de esas resoluciones ha variado naturalmente de caso a caso: en ellas se ha declarado que los actos relatados en el caso constituyen prima facie una violación de los derechos humanos 29 , o recomendado una amplia investigación de lo que parecía constituir una violación de los derechos humanos 30 , o decidido archivar el caso sin perjuicio hasta que los resultados de una investigación en curso se tomaren conocidos 31 , o declarado que no se comprobó la existencia de la violación de derechos humanos alegada en la reclamación. 32

25 Caso $\mathrm{n}^{2}$ 1744, IACHR, Report 32nd Session - 1874, p. 33.

26 Caso n $^{2} 1744, \mathrm{CIDH}$, Inforne Anual Correspondiente a 1975, pp. 177-178.

27 Así, las resoluciones fueron adoptadas después que la Comisión verificó que inter alia no había "ningún otro proceso o recurso intemo pendiente de decisión": caso n 1783, CIDH, Informe Anual - 1977, p. 48; caso $n^{2} 1870$, in ibid., p. 51.

28 Caso n$^{9}$ 1683, IACHR, Report 25th Session - 1971, p. 22, y Report 26th Session - 1971, pp. 19-22, y Report 27th Session - 1972, pp. 20-24, e Report 28th Session - 1972, pp. 22-27, y Report 29th Session - 1972, p. 25; caso $\mathrm{n}^{2}$ 1684, IACHR, Report 25th Session - 1971, pp. 22-29, y Report 26th Session - 1971, pp. 22-25, y Report 27th Session - 1972, p. 19, y Report 28th Session - 1972, pp. 15-22, y Report 29th Session - 1972, pp. 25-26, y Relatório 30a. Sessao - 1973, pp. 17-18; caso n¹701, IACHR, Report 28th Session - 1972, pp. 4-5 y 7; caso $\mathrm{n}^{2} 1697$, IACHR, Report 27th Session-1972, pp. 24-26, y Report 28th Session - 1972, pp. 8-10, y Report 29th Session - 1972, pp. 11-13.

29 Caso $n^{2}$ 1683, IACHR, Report 28th Session - 1972, pp. 26-27, y Report 29th Session - 1972, p. 25 caso $\mathrm{n}^{\circ}$ 1688, IACHR, Report 28th Session - 1972, pp. 33 y 36. Las resoluciones, además, solicitaron que se estendiese reparación a las víctimas.

30 Caso n $^{9}$ 1684, IACHR, Report 28th Session - 1972, pp. 21-22, y Report 29th Session - 1972, pp. 25-26.

31 Caso no 1701, IACHR, Report 28th Session - 1972, p. 7.

32 Caso n $^{2}$ 1715, IACHR, Report 29th Session - 1972, p. 24. 
En determinada ocasión la Comisión indicó expresamente, como cuestión de principio, que los recursos intemos que debían ser agotados (en el ámbito del sistema interamericano) comprendían solamente los recursos de naturaleza judicial: la regla de los recursos intemos no implica que el reclamante tenga que agotar todos los medios de reparación disponibles bajo la jurisdicción del Estado, sino solamente aquellos de naturaleza judicial, siempre que no se presenten rechazos o retrasos injustificados en la Administración de justicia.33

La Comisión también adoptó resoluciones que aplican, como se verá seguidamente, la presunción de ineficacia de los recursos intemos (cf. infra). Además, en dos casos recientes, objeto de resoluciones adoptadas el 25 de junio 1981, la Comisión entendió que habían sido agotados los recursos judiciales intemos y debidamente observadas las reglas del procedimiento judicial del país en cuestión. 34

\section{f) Presunción de Ineficacia de los Recursos Internos}

En numerosos casos35, la Comisión presumió verdaderos los hechos denunciados, en aplicación del artículo 51 de su antiguo Reglamento. En un caso llegó a una "vehemente presunción" de ocurrencia de graves violaciones de derechos humanos.36 En otras ocasiones la Comisión, después de solicitar informaciones adicionales sobre el agotamiento de los recursos intemos, aplicó del mismo modo la presunción de ocurrencia de actos que violan los derechos humanos. 37 En otro caso, la Comisión presumió ineficaces los recursos internos, cuando el país en cuestión - como en el cas d'espèce - se encontrase en virtual "estado de guerra", y los tribunales nacionales estubiesen sujetos, así, a ingerencias de las autori-

33 Caso no 1697, también levanco a la adopción de resolución; IACHR, Report 29th Session - 1972, pp. 11-12.

34 Caso $n^{0} 3102$, CIDH, Informe Anual - 1981-1982, p. 93; caso no 3115, in ibid., p. 95.

35 E.g., caso $n^{2} 1757, \mathrm{CIDH}$, Inforne Anual Correspondiente a 1974, p. 31; caso $\mathrm{n}^{2} 1798, \mathrm{CIDH}$, Inforne Anual Correspondiente a 1975, p. 29; caso $n^{2} 1742$, in ibid., p. 33; caso $n^{\circ} 1805$, in ibid., pp. 39-40; caso $n^{2} 1834$, in ibid., pp. 42-43; caso $n^{2} 1847$, in ibid., p. 45; caso $n^{2} 1790$, in ibid., p. 49; caso $n^{\circ} 1874$, in ibid., p. 55; casos $n^{9}$ s. 1702,1748 y 1755, in ibid., p. 60; caso $n^{\circ} 1905$, in ibid., p. 65 ; caso $n^{2} 1835$, in ibid., p. 82 ; caso $n^{2} 1887$, in ibid., p. 101; caso $n^{2} 1867$, in ibid., p. 125 ; caso $n^{9} 1875$, in ibid., p. 127; caso $n^{2} 2006$, CIDH, Informe Anual - 1977, p. 36; caso $n^{2} 2018$, in ibid., p. 38; caso $n^{9} 2021$, in ibid., pp. 39-40; caso $n^{9} 2029$, in ibid., p. 41; caso $n^{9} 2076$, in ibid., p. 43; caso $n^{2} 1967$, in ibid., p. 54; caso $n^{2} 2450, C I D H$, Informe Anual - 1978, pp. 41-42; caso $n^{2} 2291$, in ibid., p. 51; caso $n^{9} 2662$, in ibid., pp. 53-54; caso $n^{2} 2720$, in ibid., pp. 58-59; caso $n^{2} 2721$, in ibid., pp. 60-61; caso $n^{2} 2722$, in ibid., p. 63; caso $n^{2} 2756$, in ibid., p. 70; caso $n^{2} 2757$, in ibid., pp. 72-73; caso $n^{9} 2758$, in ibid., pp. 74-75; caso $n^{9} 2759$, in ibid., pp. 77-78; caso $n^{9} 2760$, in ibid., p. 80; caso $n^{9} 1909$, in ibid., p. 110; caso $n^{9} 2155, C I D H$, Informe Anual - 1979-1980, p. 46; caso $n^{9}$ 2209, in ibid., pp. 47-49; caso $\mathrm{n}^{9} 2484$, in ibid., p. 53.

36 Caso $n^{9} 1684$, CIDH, Informe Anual Correspondiente a 1973, p. 72.

37 Casos nºs. 1702 y 1748, IACHR, Report 32nd Session - 1974, pp. 44 y 51; caso no 2777, CIDH, Informe Anual - 1979-1980, pp. 62-64. 
dades militares. ${ }^{38}$ Ya aconteció, también, que la Comisión, después de examinar la petición, concluyese que había habido un "retardo injustificado" en la decisión definitiva en relación con los recursos de la jurisdicción interna. 39

En otra ocasión, la Comisión, después de verificar que recursos sucesivos de habeas corpus y apelaciones a las autoridades gubernamentales y militares del país en cuestión no surtieron efecto, aplicó la presunción de configuración de graves violaciones de los derechos humanos. $40 \mathrm{Y}$ en un caso reciente la Comisión concluyó inter alia que la prolongada detención del reclamante excedía todo criterio de "razonabilidad" y que equivalía a un acto violatório de los derechos humanos. 41

Hoy se admite, igualmente, por el artículo 39 del nuevo Reglamento de la Comisión Interamericana (aprobado el 8 de abril de 1980), que, del examen de una petición, se pueda presumir que los hechos en ella relatados son verdaderos si, en un plazo máximo de 120 dias, el gobiemo reclamado no suministra las informaciones pertinentes solicitadas por la Comisión. Con base en ese nuevo artículo 39, la Comisión ha aplicado tal presunción en sucesivos y numerosos casos 42 , en uno de ellos, v.gr., después de solicitar informaciones al gobiemo en cuestión precisamente sobre si "se agotaron o no los recursos de la jurisdicción interna"43, - continuando de esta manera con la misma orientación que tenía bajo el antiguo Reglamento. En otros cuatro casos, objeto de resoluciones adoptadas el 8 de marzo de

38 Caso no 1774, IACHR, Report 32nd Session - 1974, p. 40.

39 Caso n² 2126, CIDH, Informe Anual - 1978, p. 85.

40 Cason $^{2} 2266, \mathrm{CIDH}$, Informe Anual - 1979-1980, pp. 49-51.

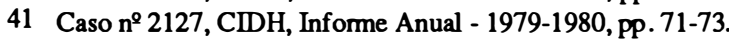

42 Caso $n^{2} 7739$, CIDH, Informe Anual 1980-1981, pp. 58-59; caso $n^{2} 7458$, in ibid., p. 60; caso $n^{\circ}$ 7378 , in ibid., p. 65 ; caso $n^{9} 7379$, in ibid., p. 67 ; caso $n^{\circ} 7383$, in ibid., p. 68 ; caso $n^{0} 7403$, in ibid., p. 72; caso $\mathrm{n}^{9} 7464$, in ibid., p. 73; caso $\mathrm{n}^{9} 7490$, in ibid., p. 76; caso $\mathrm{n}^{9} 7581$, in ibid., p. 78; caso $^{2} 7585$, in ibid., p. 82; caso $n^{9} 4425$, in ibid., p. 88; cason $^{2} 2299$, in ibid.,pp. 89-90; caso $n^{\circ}$ 3347 , in ibid., p. 91; caso $n^{9} 3496$, in ibid., p. 92; caso $n^{9} 3992$, in ibid., p. 93; caso $n^{9} 3956$, in ibid., p. 94; caso $n^{\circ} 3884$, in ibid., p. 95; caso $n^{9} 4402$, in ibid., pp. 96-97; caso $n^{\circ} 4429$, in ibid., p. 99; caso $n^{9} 4677$, in ibid., p. 101; caso $n^{9} 7486$, in ibid., pp. 102-103; caso $n^{\circ} 7455$, in ibid., p. 104; caso $n^{9} 7473, \mathrm{CIDH}$, Informe Anual - 1981-1982, pp. 36-37; caso $\mathrm{n}^{2} 2931$, in ibid., p. 51; caso $\mathrm{n}^{\circ}$ 4666 , in ibid., p. 53; caso $n^{9} 4665$, in ibid., p. 58; caso $n^{0} 4288$, in ibid., p. 60 ; caso $n^{2} 2300$, in ibid., pp. 68-69; caso $n^{9} 7898$, in ibid., pp. 70-71; caso $n^{2} 7899$, in ibid., p. 72; caso $n^{9} 6091$, in ibid., pp. 77-78; caso $n^{9} 6093$, in ibid., p. 80; caso $n^{9} 7602$, in ibid., p. 82; caso $n^{\circ} 7776$, in ibid., p. 84; caso $\mathrm{n}^{2} 7778$, in ibid., pp. 85-86; caso $\mathrm{n}^{2} 7777$, in ibid., pp. 87.88; caso $\mathrm{n}^{9} 7821$, in ibid., p. 89; caso $\mathrm{n}^{9} 7822$, in ibid., p. 91; caso $\mathrm{n}^{2}$ 2401, CIDH, Informe Anual - 1982-1983, p. 68; casos $\mathrm{n}^{9}$ s. 2646, 2647 y 2648, in ibid., pp. 71,75 y 78-79; caso $n^{\circ} 2650$, in ibid., p. 81; casos nos. 2652 y 2653, in ibid., pp. 64 y 86-87; caso $n^{9} 2973$, in ibid., pp. 88-89; caso $n^{9} 3096$, in ibid., pp. 90-91; caso $n^{9} 3519$, in ibid., pp. 92-93; caso $n^{9} 6586$, in ibid., p. 95; caso $n^{9} 5154$, in ibid., pp. 105-106; caso $\mathrm{n}^{\mathrm{9}} 7238$, in ibid., p. 107; caso $\mathrm{n}^{\mathrm{0}} 7245$, in ibid., p. 109; casos $\mathrm{n}^{\mathrm{9}}$ s. 7309 y 7310 , in ibid., pp. 111-112; casos $n^{9}$ s. 7313 y 6314, in ibid., pp. 114 y 116 ; caso $n^{2} 7319$, in ibid., pp. 117-118; caso $\mathrm{n}^{\mathrm{9}} 7316$, in ibid., p. 120; caso $\mathrm{n}^{\mathrm{2}} 7320$, in ibid., p. 122.

43 Caso no 7472, CIDH, Informe Anual - 1980-1981, pp. 61-62. 
1982, la Comisión afirmó expresamente que presumía que "no existen recursos internos que deban ser agotados" y que eran verdaderos los hechos denunciados. 44

\section{g) Retardos Indebidos y Denegación de Justicia}

En un caso reciente, en el que el gobiemo reclamado formuló la objeción de no-agotamiento de los recursos intemos, argumentando que existía un proceso pendiente, la Comisión contestó que tal alegación no era aceptable, a la luz del artículo 46 (2) (c) de la Convención Americana sobre Derechos Humanos, el cual rechaza la posibilidad de formular la objeción de no-agotamiento cuando haya "retardo injustificado" en la decisión sobre los recursos internos; la Comisión añadió que en ese caso además del retardo, no hubo una "firme voluntad" de las autoridades gubernamentales para "concluir las investigaciones y sancionar a los responsables por los hechos denunciados" 45 .

En otro caso, objeto de la resolución adoptada el 30 de junio de 1983, la Comisión llegó hasta, expresamente, "deplorar el retardo y la denegación de justicia"46. En efecto, el concepto de denegación de justicia se encuentra intimamente ligado al requisito del previo agotamiento de los recursos internos: una falla en estós últimos (v.gr., si se revelaren ineficaces) puede llevar a configurar la denegación de justicia, abriendo el camino para la acción internacional de protección de los derechos humanos. 47 A ese respecto, en reciente ocurrencia, la Comisión constató la denegación de justicia y la violación de los derechos humanos debido a que la víctima no había tenido la "oportunidad de defenderse" y lograr la reparación de los daños. 48

\section{h) No-Aplicación de la Regla del Agotamiento en los Denominados "Casos Generales"}

En virtud de una regla de interpretación adoptada en la II Conferencia Interamericana Extraordinária (1965)49, no se aplica la regla del agotamiento de los recursos internos a los

44 Caso $^{9} 7481$, CIDH, Informe Anual - 1981-1982, pp. 40-41; caso $n^{9} 7823$, in ibid., p. 45; caso $n^{\circ}$ 7530, in ibid., p. 42; caso $\mathrm{n}^{2} 7824$, in ibid., pp. 47-48.

45 Caso "La Pólvora", resolución n² 20/83, de 4/10/1983, in CIDH, Informe Anual - 1982-1983, pp. 137-138.

46 Caso n 7575, CIDH, Inforne Anual - 1982-1983, p. 65.

$47 \mathrm{Y}$ en el derecho intemacional general, los conceptos de denegación de justicia y agotamiento de los recursos intemos se muestran en interacción para forma la base de la mayoría de las reclamaciones intemacionales; para un estudio, cf. A. A. Cançado Trindade, "Denial of Justice and Its Relationship to Exhaustion of Local Remedies in Intemational Law", 53 Philippine Law Joumal (1978), pp. 404-420.

48 Caso $^{2}$ 2976, CIDH, Informe Anual - 1982-1983, p. 101.

49 Acto Final de la Conferencia, OEA, doc. OEA/Ser. C/I.13, p. 32. 
llamados "casos generales", i.e., casos de supuestas violaciones generalizadas de derechos humanos. En diciembre de 1968 (20 sesión de la Comisión) se prepararon y examinaron informes sobre el derecho de petición 50 y el tratamiento de peticiones en "casos individuales"51, y el tema del "Agotamiento de los Recursos Legales Internos" fue incluído en el programa general de trabajo de la Comisión, habiendo sido designado un relator. En un informe sobre el tema preșentado a la Comisión en mayo de 1972 (28 sesión), el relator concluyó categóricamente que, para los efectos del trabajo de la Comisión, la regla del agotamiento de los recursos intemos no debería ser aplicada a reclamaciones de derechos humanos en "casos generales", sino solamente en "casos individuales" 52 .

Esta regla de interpretación fue aplicada en un caso de fecha 1971-1972.53 Posteriormente, en otro caso, en su $32^{\prime}$ sesión (8 a 18 de abril de 1974), la Comisión, después de analizar el tema, decidió examinar una serie de reclamaciones de derechos humanos relacionadas entre si - que incluían la suspensión de garantías de due process y otras irregularidades, e ineficacia de los recursos de amparo y de habeas corpus - como un "caso general": el requisito del previo agotamiento de los recursos internos fue, por consiguiente, dispensado, permitiendo así a la Comisión proceder de inmediato a un estudio amplio y a fondo de la situación. 54 Cabe observar que esta significativa evolución tuvo lugar mediante un proceso de interpretación liberal de las normas que rigen el procedimiento de la Comisión Interamericana. 55

\section{i) La Carga de la Prueba en Relación con el Agotamiento}

El importante item de la carga de la prueba en relación con el agotamiento de los recursos intemos se encuentra naturalmente relacionado con algunas otras cuestiones procesales

50 OEA, doc. OEA/Ser. L/V/II.20 - doc. 20-22 y 33 Rev.

51 OEA, doc. OEA/Ser. L/V/II.21 - doc. 17. El estudio contenía "propuestas prácticas" sobre la admisibilidad de reclamaciones en "casos individuales". Esta referencia a "casos individuales" en relación a la aplicación de la regla de los recursos intemos no debería pasar desapercibida.

52 Gabino Fraga, "El Agotamiento de Recursos Intemos Previo a la Acción Internacional", OEA, doc. OEA/Ser. L/V/II.28 - doc. 19 (de 4 de mayo de 1972), pp. 7-11. Además, el rapporteur indicó tres excepciones a la regla de los recursos intemos: no-existencia de tales recursos, retardos indebidos, y casos en que el reclamante fue impedido de utilizar los recursos intemos; cf. ibid., pp. 7 11.

53 Caso no 1684, que se tomó un "leading case" sobre la materia; cf. J. Jiménez de Aréchaga, "Seminario sobre Agotamiento de los Recursos de Jurisdicción Intema (Proyecto de Programma)", OEA doc. OEA/Ser. L/V/II.29 - doc. 5, de 3/10/1972, p. 3, y cf. pp. 1-3; cf. también, sobre el caso ${ }^{9}$ 1684, IACHR, Report 31st Session - 1973, p. 30; CIDH, Informe Anual Correspondiente a 1973, pp. 63-64 y 67-68.

54 Cf. OEA, doc. OEA/Ser. L/V/II.34 - doc. 21, de 25/10/1074, pp. 1-177, para el informe de la Comisión sobre el caso (aprobado en su 34a. sesión, 22 de julio a 2 de agosto de 1974).

55 En el caso, particularmente el artículo 9 (bis) (d) de su antiguo Estatuto y el artículo 54 de su antiguo Reglamento, que disponen sobre la regla del agotamiento de los recursos intemos. 
analizadas en este estudio. Así, v.gr., de la práctica de la Comisión Interamericana de solicitar informaciones adicionales sobre el agotamiento, ya sea a los gobiemos reclamados o a los particulares reclamantes autores de la peticiones, o., lo que no es raro, a ambos (supra), se puede inferir que el onus probandi en relación con el agotamiento de los recursos internos se reparte entre reclamante y reclamado. La cuestión fue objeto de atención también en el experimento regional europeo congénero: recuérdese, a ese respecto, que la jurisprudencia de la Comisión Europea de Derechos Humanos evolucionó mucho, desde la década de los cincuenta en que hacía recaer sistemáticamente sobre el reclamante la carga de la prueba en cuanto al agotamiento de los recursos intemos, hasta hoy en día, en que distribuye, de manera más justa, equilibrada y flexible, esa carga entre el reclamante y el reclamado. Fue lo que buscamos demostrar en una investigación a ese respecto, divulgada en 1976, defendiendo la tesis de la distribución de la carga de la prueba en cuanto al agotamiento de los recursos internos entre reclamante y reclamado, en los experimentos de protección intemacional de los derechos humanos. 56

Más recientemente, la misma orientación fue expresamente adoptada por la Comisión Interamericana de Derechos Humanos: su nuevo Reglamento (aprobado el 8 de abril de 1980) dispone en su artículo 34 inter alia que "para que una petición pueda ser admitida por la Comisión, se requerirá que se hayan interpuesto y agotado los recursos de jurisdicción intema, conforme a los principios del derecho internacional generalmente reconocidos"; estas disposiciones no se aplican cuando no exista el "debido proceso legal" para la protección de los derechos, o cuando al reclamante se le haya impedido utilizar los recursos intemos, o cuando se haya verificado un "retardo injustificado" en el proceso; cuando el autor de la petición alegare la imposibilidad de agotar los recursos internos - añadió significativamente el artículo 34 del nuevo Reglamento - "corresponderá al gobiemo en contra del cual se dirige la petición demostrar a la Comisión que los recursos internos no han sido previamente agotados, a menos que ello se deduzca claramente de los antecedentes contenidos en la petición"57.

Así, v.gr., en un caso reciente, mientras el gobiemo reclamado buscaba demostrar que las decisiones de los tribunales internos estatales eran susceptibles de recursos ante la Corte Suprema, lo cual no se había hecho en eso caso, los reclamantes contraargumentaban que la jurisdicción de la Corte Suprema para examinar recursos contra decisiones de los tribunales estatales se limitaba a "situaciones específicas" no aplicables al cas d'espèce; la Comisión Interamericana, después de examinar los hechos, concluyó que "no existían procedimientos

56 A. A. Cançado Trindade, "The Burden of Proof with Regard to Exhaustion of Local Remedies in Intemational Law", 9 Revue des droits de l'homme / Human Rights Joumal - Paris (1976), pp. 81121.

57 Texto in: OEA, Manual de Normas Vigentes en Materia de Derechos Humanos, doc. OEA/Ser. L/V/II.50 - doc. 6, 1980, p. 135. 
intemos que agotar antes de recurrir a la jurisdicción international ${ }^{58}$. En otro caso, la Comisión se contentó con "estimar prima facie la veracidad de los hechos"59. Sobre este último aspecto, cabe recordar que, en el experimento regional europeo, la jurisprudencia de la Comisión Europea de Derechos Humanos evolucionó al respecto, de la exigencia de una "substantial evidence" (en los años cincuenta) a tan sólo una "prima facie evidence I commencement de preuve" (de 1960 hasta hoy).60

En otra ocasión, la Comisión Interamericana estableció que el simple hecho de que los recursos intemos hubiesen sido agotados y de que hubiese una decisión judicial definitiva que hubiese examinado las pruebas presentadas por los reclamantes no impedía que la propia Comisión considerase si tales pruebas demostraban una violación de los derechos humanos.61 En otro caso, la Comisión dedujo del examen de las pruebas ("claras evidencias") la veracidad de los hechos denunciados. 62 Y, en un caso reciente, en que declaró que el gobiemo en cuestión había cometido una violación de los derechos humanos, la Comisión señaló inter alia que el gobiemo reclamado no había suministrado prueba alguna que le permitiera determinar si quedaba por agotar algún recurso de la jurisdicción intema.63 Con las recientes modificaciones, de marzo de 1985, del Reglamento de la Comisión, el artículo 34 del nuevo Reglamento (supra) pasó a ser numerado como artículo 37.64

\section{j) La Verificación del Agotamiento en el Trámite de las Peticiones}

En la práctica, la propia Secretaria de la Comisión Interamericana ha iniciado el trámite de una petición, aunque no esté resuelto el problema del agotamiento de los recursos intemos. La Secretaria, excepcionalmente, se ha negado a iniciar el trámite de la petición por falta del agotamiento de los recursos intemos en dos circunstancias: cuando aparece claramente que los recursos internos no fueron efectivamente agotados y los hechos denunciados no afectaren de forma inmediata el derecho a la vida, a la libertad o a la seguridad personal, existiendo en el Estado en cuestión un sistema judicial independiente, en condiciones de poder pronunciarse sobre los hechos denunciados; y cuando la petición denuncia detención arbitraria o falta de due process, siendo la acusación del delito por tráfico de drogas o delito común similar. En estos dos casos la Secretaria de la Comisión ha comunicado al autor de

58 Caso $n^{2} 2141$, CIDH, Inforne Anual - 1980-1981, pp. 39-40.

59 Caso n 3482, CIDH, Inforne Anual - 1980-1981, p. 29.

60 A. A. Cançado Trindade, "The Burden of Proof ...", op. cit. supra n. 56, pp. 88-91 y 110.

61 Caso n 1752, IACHR, Report 31st Session - 1973, p. 49.

62 Caso $n^{2} 4326, \mathrm{CIDH}$, Informe Anual - 1981-1982, pp. 25-26.

63 Caso n 1954, CIDH, Informe Anual - 1981-1982, p.97.

64 Cf. texto in: Manual de Normas Vigentes en Materia de Derechos Humanos, doc. OEA/Ser. L/V/II.65 - doc. 6, 1985, pp. 127-128. 
la petición que ésta no puede ser atendida por no-agotamiento de los recursos intemos, o que necesita obtener mayores informaciones para iniciar el proceso. 65

En un segundo momento, la propia Comisión, naturalmente, se ha pronunciado sobre la cuestión, durante el trámite de un caso o al adoptar una resolución (cf. supra). El trámite, conducente a la adopción de la resolución por la Comisión, prosigue si el gobierno en cuestión no envia observaciones en cuanto a la falta de agotamiento de los recursos internos, $\mathrm{y}$, evidentemente, si el propio gobierno admite la falta de recursos internos. Al dar proseguimiento al trámite del caso, la Comisión ha verificado, en particular, la existencia de órganos judiciales independientes. Por último, la Comisión ha, además, en un tercer momento, aplicado la regla de los recursos internos, una vez adoptada la resolución, al tomar conocimiento de un pedido de reconsideración formulado por un gobierno. Todo ésto transparenta la flexibilidad en la aplicación de la regla de los recursos internos, todavia más realizada por el hecho de que en la gran mayoria de los casos (e.g., los casos relativamente recientes sobre personas detenidas o sobre desaparecidos en Argentina) la Comisión no ha formulado una declaración expresa o formal de admisibilidad de los casos. Tal práctica ha contado con la aquiescencia de los Estados, pero podrá en el futuro suscitar dificultades en relación con los Estados Partes en la Convención Americana sobre Derechos Humanos que reconocieron la jurisdicción de la Corte Interamericana; así, no sorprende que la propia Secretaria de la Comisión haya sugerido recientemente que la Comisión debería siempre emitir un pronunciamiento formal en cuanto a la admisibilidad de las peticiones, y particularmente en cuanto al agotamiento o no de los recursos internos. 66

2. El Agotamiento de los Recursos Internos en la Jurisprudencia de la Corte Interamericana de Derechos Humanos

Aunque sea la Comisión Interamericana el órgano encargado de pronunciarse sobre cuestiones referentes a la admisibilidad de peticiones que contienen denuncias sobre violaciones de derechos humanos, también la Corte Interamericana - establecida en 18 de julio de 1978, por ocasión de la entrada en vigor de la Convención Americana sobre Derechos Humanos - tuvo oportunidad de manifestarse acerca del tema (cf. infra). Existe aquí un paralelo con el experimento regional europeo, en el cual, a la par de la vasta jurisprudencia de la Comisión Europea de Derechos Humanos, también se promovió el pronunciamiento de la Corte Europea sobre la materia.67 En el ámbito regional interamericano la Corte

65 E. Vargas, "El Agotamiento de los Recursos Intemos", doc. A.III, Washington, Secretaría de la C.I.D.H., 1984, pp. $11-14$ (mimeografado, circulación intema).

66 Ibid., p. 11-14; E. Vargas, "La Admisibilidad de una Denuncia: Sus requisitos y Su Oportunidad", doc. A.I, Washington, Secretaría de la C.I.D.H., 1984, pp. 3-6 (mimeograf ado, circulación intema).

67 Para un estudio de la jurisprudencia de la Corte Europea sobre la materia, cf. A. A. Cançado Trindade, "Exhaustion of Local Remedies in the Jurisprudence of the European Court of Human 
Interamericana se deparó inicialmente con esta cuestión en el caso Viviana Gallardo et alii versus Costa Rica (1981); antes de llevar el asunto ante la Comisión, el gobiemo en cuestión dirigió una petición a la Corte para determinar si había habido violación de los derechos humanos consagrados en la Convención Americana en el caso de la muerte de Viviana Gallardo en una prisión y de las lesiones sufridas por sus compañeras de celda. Para efectos del caso, el gobiemo de Costa Rica renunció formalmente al procedimiento ante la Comisión y al requisito del previo agotamiento de los recursos de la jurisdicción interna.68

En la decisión del 13 de noviembre de 1981 acerca de este caso, la Corte, después de advertir que el procedimiento ante la Comisión no había sido concebido en interés exclusivo del Estado, y por lo tanto no era, en principio, renunciable, se detuvo en la cuestión de la renuncia a la regla del agotamiento: inicialmente recordo, correctamente, que, de acuerdo con la jurisprudencia internacional a ese respecto, el requisito en cuestión es susceptible de renuncia, aunque tácita. La cuestión de saber si se cumplieron o no los requisitos de admisibilidad de una petición ante la Comisión - añadió la Corte -, es un tema que concierne a la propia interpretación o aplicación de la Convención (artículos 46-47), y, por ello, de competencia ratione materiae de la Corte. En el caso concreto, sin embargo, le correspondería en princípio a la Comisión pronunciarse en primer lugar sobre tales requisitos de admisibilidad de la petición; como ésto no había ocurrido, la Corte, entendiendo que así no podría examinar directamente el caso, evitó en aquella etapa pronunciarse acerca del alcance y valor de la renuncia del gobiemo de Costa Rica a la regla del previo agotamiento de los recursos intemos.69 Así, la demanda no fue admitida y el caso fue remetido para examen de la Comisión 70 no implicando tal remisión una decisión de la Corte acerca de la competencia de la Comisión.71

Más recientemente se volvió a plantear la cuestión del previo agotamiento de los recursos de derecho interno en los casos Velásquez Rodriguez, Godinez Cruz, y Fairén Garbi y Solis Corrales, relativos a Honduras. En éstos tres casos hondureños, la Comisión Interamericana, aplicando el criterio de la probabilidad razonable de obtener remedio, argumentó delante de la Corte que se trataba, en los casos, de "prácticas estatales", "prácticas constitutivas de violaciones masivas y sistemáticas de derechos humanos", en las cuales se comproba la inefectividad del poder judicial en casos, como los presentes, de desaparicio-

Rights: An Appraisal", 10 Revue des droits de l'homme / Human Rights Joumal - Paris (1977), pp. 141-185.

68 Cf. Inforne Anual de la Corte Interamericana de Derechos Humanos - 1981, p. 11.

69 Informe Anual de la Corte Interamericana de Derechos Humanos - 1982, pp. 18-19.

70 Cf. ibid., p. 20. La Comisión, porla resolución $n^{2} 13 / 83$, del 30/06/1083, declaró la petición inadmisible y archivó el caso; cf. CIDH, Informe Anual - 1982-1983, pp. 51-55.

71 Cf. CIDH, Inforne Anual - 1982-1983, p. 52. Y cf. Corte Interamericana de Derechos Humanos, asunto de Viviana Gallardo y Otras, doc. n G 101/81, de 1981, pp. $22-26$. 
nes forzadas de personas. Así, se tomaba innecesario insistir en la regla del agotamiento de los recursos de la jurisdicción intema, y el peso de la prueba correspondía al gobierno que invocaba aquella objeción. 72 En resumen, no había recursos eficaces a agotar.

En su sentencia del 26 junio de 1987 sobre las Excepciones Preliminares en los tres casos hondureños (supra), la Corte Interamericana desarrolló dos líneas de consideraciones: sobre el rationale de la regla del agotamiento de recursos intemos en el presente contexto, y sobre la interrelación de las funciones de la Corte y de la Comisión en la aplicación de la regla. En cuanto a los princípios de derecho internacional generalmente reconocidos sobre la materia, la Corte destacó la posibilidad de renuncia expresa o tácita de la regla del agotamiento, la oportunidad de invocar a ésta en las primeras etapas del procedimiento (a falta de lo cual podrá presumirse la renuncia tácita de la misma), y la carga de la prueba (en cuanto a los recursos que deben agotarse y a su efectividad) a cargo del Estado. Acrecentó la Corte que, cuando se invocan ciertas excepciones a la regla del agotamiento, "no sólo se está alegando que el agraviado no está imputando al Estado involucrado una nueva violación a las obligaciones contraídas por la Convención. En tales circunstancias la cuestión de los recursos intemos se aproxima sensiblemente a la materia de fondo. (...) La inexistencia de recursos internos coloca a la víctima en estado de indefensión y explica la protección internacional"73.

La Comisión había sostenido que, por ser la regla del agotamiento un requisito previo de admisibilidad ante ella (Comisión), no era una condición para admitir las demandas interpuestas ante la Corte, la cual no estaría facultada para revisar lo decidido por la Comisión en la etapa de admisibilidad. En cambio, la Corte, distintamente, sostuvo que la materia caía dentro de su competencia contenciosa por tratarse de cuestión relativa a la interpretación o aplicación de la Convención. Consideró la Corte que ejercía jurisdicción plena sobre todos los casos o cuestiones relativas a la interpretación o aplicación de la Convención, estando habilitada para sentenciar libremente, de acuerdo con su propia evaluación, no vinculada con lo que haya previamente decidido la Comisión. En los tres casos hondureños presentes, la Corte resolvió unir la objección de no-agotamiento interpuesta por Honduras a la cuestión de fondo, "dada la imbricación del problema de los recursos intemos con la violación misma de los derechos humanos"74.

72 Para los argumentos de la Comisión, cf.: caso 7920, Velásquez Rodriguez, doc. OEA/Ser. L/V/II.69 - doc. 6, del 16 de marzo de 1987, pp. 44-61; caso 8097, Godinez Cruz, doc. OEA/Ser. L/V/II.69 - doc. 8, del 16 de marzo de 1987, pp. 17-32; caso 7951, Fairen Garbi y Solis Corrales, doc. OEA/Ser. L/V/II.69 - doc. 7, del 16 de marzo de 1987, pp. 32-52.

73 Corte Interamericana, sentencias del 26 de junio de 1987, Excepciones Preliminares: caso Velasquez Rodriguez, Serie C, n 1, pp. 38-40; caso Fairen Garbi y Solis Corrales, Serie C, n² 2, pp. $40-$ 42; caso Godinez Cruz, Serie C, $\mathrm{n}^{\mathrm{3}} 3$, pp. 37-40.

74 Ibid., Serie C, $n^{2} 1$, pp. 36 y 41-43; Serie C, $n^{2} 2$, pp. 38 y 43-45; Serie C, $n^{2} 3$, pp. 35-36 y 41-42. 
Finalmente, en su sentencia del 29 de julio de 1988 en el caso Velásquez Rodriguez, la Corte precisó que si un Estado alega el no-agotamiento de deteminados recursos internos corresponderá a la parte contraria demostrar que tales recursos fueron agotados o que el caso caía dentro de las excepciones (art. 46 (2) de la Convención). Era deber jurídico de los Estados proporcionar tales recursos, y la remisión a "los principios del derecho internacionales generalmente reconocidos" se refería no sólo a la existencia de tales recursos sino también a que éstos fueran efectivos y adecuados (como resulta de las excepciones a la regla). 75 En la explicación de la Corte, un recurso es eficaz si es "capaz de producir el resultado para el que ha sido concebido", y es adecuado si su función es "idónea para proteger la situación jurídica infringida"76.

La Corte tomó en debida consideración la argumentación de la Comisión en el sentido de que en los casos de desapariciones el hecho de haber intentado un hábeas corpus o un amparo sin éxito era "suficiente para tener por agotados los recursos de la jurisdicción interna si la persona detenida sigue sin aparecer". La regla del agotamiento no debía entenderse como "la necesidad de efectuar, mecánicamente, trámites formales"; en Honduras hubo, entre los años 1981 y 1984, una "práctica de desapariciones" forzadas o involuntarias de personas "dispuesta o tolerada por el poder público" que "imposibilitaba agotar los recursos internos", i.a., que tomaba estos últimos (recursos de exhibición personal y acciones penales) ineficaces o meramente formales. 77 Sobre la cuestión, concluyó la Corte que las pruebas aportadas por la Comisión no fueron desvirtuadas y eran suficientes para "rechazar la excepción preliminar del Gobiemo sobre inadmisibilidad de la demanda por el no agotamiento de los recursos intemos"78. Como ya se señalo (cf. Parte II, item IV-1, supra), en el presente caso Velasquez Rodriguez, así como en el caso Godinez Cruz, la Corte declaró que Honduras violó la Convención Americana sobre Derechos Humanos (artículos 7, 5 y 4 en conexión con el artículo 1 (1), de la Convención), mientras que en el caso Fairén Garbi y Solis Corrales la Corte concluyó que no había sido probado que los dos individuos habían desaparecido por causa imputable a Honduras, cuya responsabilidad no había quedado, por consiguiente, establecida.

75 Corte Interamericana de Derechos Humanos, caso Velasquez Rodriguez, sentencia del 29 de julio de 1988, Serie $C, n^{2} 4$, pp. 26-28. Algunos años antes de la decisión de la Corte, estos puntos fueron sostenidos y desarrollados in: A. A. Cançado Trindade, The Application of the Rule of Exhaustion of Local Remedies in Intemational Law, Cambridge, Cambridge University Press, 1983, pp. 1-412; y para un estudio pionero y completo sobre la distribucion o división de la carga de la prueba en relación al agotamiento de los recursos intemos, cf. A. A. Cançado Trindade, "The Burden of Proof ...", op. cit. supran. 56.

76 Corte Interamericana de Derechos Humanos, caso Velasquez Rodriguez, cit. supra, Serie C, $\mathrm{n}^{0} 4$, pp. 28-29.

77 Ibid., pp. 30-31 y 33-35. En estos numerosos casos de secuestro y desaparición de personas, entendía la Comisión que la carga de la prueba en materia de recursos intemos le correspondía al gobiemo (ibid., p. 31).

78 Ibid., pp. 35 y 79. 


\section{Evaluación y Perspectivas}

Al pronunciarse sobre la admisibilidad de peticiones conteniendo alegaciones de violaciones de derechos humanos la Comisión Interamericana profiere decisiones de naturaleza más bien administrativa que propriamente judicial: tal vez ésto le haya permitido actuar con flexibilidad y evitar el rechazo inmediato de ciertas peticiones con base en condiciones de admisibilidad tales como el requisito del previo agotamiento de los recursos internos. La Comisión Europea, en contraposición, ha procedido con mayor rigor, tal vez debido al hecho de que sus decisiones sobre admisibilidad de peticiones asumen un carácter judicial. A la Comisión Interamericana, por su parte, por una serie de técnicas procesales y por la razón básica indicada anteriormente, le ha sido posible utilizar presunciones más favorables a los reclamantes en lo que se refiere a las condiciones de admisibilidad de sus peticiones. En la aplicación de la regla de los recursos intemos en la etapa de la admisibilidad, la Comisión Interamericana ha adoptado una diversidad de soluciones (v.gr., archivo temporal en lugar de simple rechazo, solicitudes de informaciones adicionales79, aplazamiento del examen y decisión, etc. - cf. supra). En síntesis, la Comisión Interamericana parece estar menos inclinada que la Comisión Europea, a rechazar, expresamente, una petición como inadmisible por no-agotamiento de los recursos internos. 80

En lo referente a la dispensa o renuncia por la Comisión Interamericana del requisito del previo agotamiento de los recursos intemos en los llamados "casos generales" (supra), es significativo observar que este desarrollo encuentra paralelos tanto en el plano regional como en el global. Así, v.gr., la Comisión Europea, en los ultimos años, se ha inclinado, en algunos casos, por la dispensa del requisito del previo agotamiento de los recursos internos, cuando una petición suscitare la cuestión de la compatibilidad de supuestas "medidas legislativas y prácticas administrativas" (a nivel nacional) con la Convención Europea, en particular cuando las alegaciones estuvieren bien fundamentadas; así, la Comisión Europea ha dado, ademas a la noción de "víctima" (bajo la Convención) una interpretación cada vez más amplia. En el ámbito de las Naciones Unidas, el sistema conocido como el de la resolución 1503 (XLVIII) de 1970 del ECOSOC abarca las peticiones - seleccionadas y enviadas a la Comisión de Derechos Humanos de la ONU para estudio o investigación que necesariamente deben referirse a "determinadas situaciones que parezcan revelar un padrón consistende de violaciones flagrantes de derechos humanos, seguramente compro-

79 A ese respecto, la Comisión parece haber actuado con base en el principio de que la carga de la prueba en relación con el agotamiento de los recursos intemos se distribuye entre el reclamante y el reclamado.

80 Para dados estatísticos, cf. Conselho da Europa, doc. DH (75) 4, de 1/10/1975, pp. 65-72. E cf. observaciones recientes de la Comisión Interamericana sobre las peticiones recibidas, in IACHR, Annual Report - 1977, doc. OEA/Ser. L/V/II.43 - doc. 21, de 20/4/1978, pp. 30-58. 
badas" 81 . No se trata aqui, por lo tanto, de remediar violaciones individuales de derechos humanos, por cuanto su implementación está más propiamente dirigida a situaciones prevalecientes (que afectan grupos o colectividades humanas), con implicaciones para la aplicación de la regla del agotamiento de los recursos internos.

De ese modo, es alentador constatar que la práctica de la Comisión Interamericana sobre el particular (supra), incluso antes de la entrada en vigor - a mediados de 1978 - de la Convención Americana sobre Derechos Humanos, se coaduna con las experiencias paralelas de la Comisión Europea de Derechos Humanos (bajo la Convención Europea) y de la Comisión de Derechos Humanos de la ONU (bajo el sistema de la resolución 1503 del ECOSOC), dirigidas todas a facilitar gradualmente el acceso de particulares lesionados a las instancias internacionales, y fortalecer así su posición en el plano internacional, en experimentos provistos ya sea de base convencional. o de base originalmente constituída por instrumentos técnicamente no obligatórios (resoluciones de organismos internacionales), pero que no por eso dejan de ejercer efectos jurídicos en relación con los Estados miembros. 82

Se puede preguntar, ademas, si las singularidades de la práctica de la Comisión Interamericana sobre la aplicación de la regla del agotamiento (v.gr., aplazamiento de la continuación del examen de peticiones debido al no-agotamiento, solicitud de informaciones adicionales sobre el agotamiento, archivo de casos sin perjuicio de la reapertura del examen de los mismos) representan una nueva corriente, original y válida, en la aplicación de aquella regla en un experimento de derecho internacional sobre protección de derechos humanos, o si, por el contrario, entran en conflicto con los "principios de derecho internacional generalmente reconocidos" sobre el tema. Con todo, la referencia a la aplicación de la regla del agotamiento de acuerdo con los "principios de derecho intemacional generalmente reconocidos", incorporada en el artículo 26 de la Convención Europea de Derechos Humanos, no se encuentra en el artículo 9 (bis) (d) del antiguo Estatuto de la Comisión Interamericana o en el artículo 54 de su antiguo Reglamento y tampoco se encuentra en el artículo 20 (c) de su nuevo Estatuto o en los articulos 29 (d) y 32 (a) de su nuevo Reglamento. Sin embargo, vuelve a aparecer en el artículo 34 (1) del nuevo Reglamento en el artículo 46 (a) de la Convención Americana sobre Derechos Humanos. La omisión, en las primeras disposiciones, parece haber sido deliberada, dado que los redactores de los instrumentos que regulan el sistema interamericano de protección de los derechos humanos estuvieron en general

81 Resolución 1503 (XLVIII) del ECOSOC, § 5; resolución 1 (XXIV) de la Subcomisión de Prevención de Discriminación y Protección de Minorias, § 1 . Obsérvese que, en virtud del $\S 8$ de la resolución 1503 (XLVIII) del ECOSOC, las medidas de implementación tomadas permanecen confidenciales.

82 A. A. Cançado Trindade, "The Evolution of the O.A.S. System of Human Rights Protection: An Appraisal", 25 German Yearbook of International Law / Jahrbuch für intemationales Recht (1982), pp. 505 y $513-514$. 
conscientes de las disposiciones - semejantes o equivalentes - existentes en otros experimentos congéneres de protección internacional de los derechos humanos. 83 De todas maneras, debe tenerse en cuenta que la incorporación de la referencia al derecho internacional general, en disposiciones sobre la regla del agotamiento, de instrumentos internacionales de protección de los derechos humanos, no buscaba atribuir a aquella regla un carácter absoluto, sino, por el contrario, resaltar la necesidad de flexibilidad en su aplicación en ese contexto de protección, frente, v.gr., a las excepciones, generalmente reconocidas, propiciadas por atrasos indebidos y denegación de justicia84 - punto éste no siempre claramente comprendido.

Afortunadamente la más reciente jurisprudencia de la Corte Interamericana sobre la materia ha traído aclaraciones significativas sobre este punto (el alcance de las excepciones) así como sobre las cuestiones de la renuncia expresa o tácita de la regla y la distribución de la carga de la prueba en cuanto al agotamiento. La Corte ha aplicado, ademas, el criterio de la probabilidad razonable de éxito en la utilización de un recurso, y ha insistido en la necesidad de eficacia de los recursos intemos; la Corte ha señalado, con toda pertinencia, que en los casos de desapariciones de personas como "práctica estatal" o con la negligencia o tolerancia del poder público hay una presunción en favor de las víctimas, y no hay que insistir en la aplicación de la regla del agotamiento (pues no hay recursos que agotar). La contribución de la Corte, que apunta en la dirección correcta, permitirá un desarrollo en la aplicación de la regla del agotamiento con atención a las particularidades del presente contexto de protección internacional de los derechos humanos.

Hay, además, elementos que, en realidad, permiten deducir que se le ha dado a la regla de los recursos intemos un sentido especial, propio al sistema interamericano de protección, lo que equivaldría a una aplicación especial de la regla en ese contexto regional85; dificil-

83 Cf., e.g., OEA, doc. OEA/Ser. L/V/II.16 - doc. 20, pp. 10-12.

84 A. A. Cançado Trindade, "Exhaustion of Local Remedies in the 'Travaux Préparatoires' of the European Convention on Human Rights", 58 Revue de droit intemational de sciences diplomatiques et politiques (1980), pp. 73-88.

85 Acrecéntese, además, que el derecho de petición individual en el sistema interamericano es otorgado ampliamente (a "peticionatios", "presuntos lesionados", "personas denunciantes") - artículo 9 (b9s) del antiguo Estatuto de la Comisión Interamericana, antículo 38 de su antiguo Reglamento, artículos 29, 34 y sobretodo 36 (2) (b) ("peticionario" tercera persona, sin mandato de la presumida víctima o su familia), artículos 44 y 46 de la Convención Americana, - y no solamente, como en el experimento europeo congénere, a víctimas individuales de las violaciones de las cuales se queja, si bien el concepto de "víctima" tenga en los últimos años se ecpandido, desde una interpretación inicialmente estricta hasta una interpretación cada vez más amplia, bajo la Convención Europea; cf. A. A. Cançado Trindade, "Exhaustion of Local Remedies in Relation to Legislative Measures and Administrative Practices - the European Experience", 19 Malaya Law Review (1976), pp. $257-$ 280; A. A. Cançado Trindade, "Co-Existence and Co-ordination of Mechanisms of Intemational 
mente, sin embargo, se podría argumentar que la aplicación de la regla en el sistema interamericano no esté de acuerdo con el derecho intemacional. Su no aplicación por la Comisión Interamericana, por ejemplo, en los llamados "casos generales", encuentra paralelos en experimentos congégeneres de protección internacional de los derechos humanos tanto a nivel regional como global. La incidencia de la regla del agotamiento en ese contexto es por cierto distinta de su aplicación en la práctica de la protección diplomática de nacionales en el exterior (en el derecho intemacional consuetudinario), pero la regla en cuestión siempre estuvo lejos de tener las dimensiones de un principio inmutable o sacrosanto de derecho intemacional. Además, los dos contextos - protección diplomática y protección de los derechos humanos - también son distintos, y no parece existir ningún factor que impida la aplicación de la regla con mayor o menor rigor en esas situaciones diferentes, y la interpretación de la misma por directrices distintas que, aunque distinta, no por eso se desvian o se apartan ipso facto y necesariamente de los principios del derecho internacional generalmente reconocidos. 86

Al proferir decisiones de naturaleza más bien administrativa que propriamente judicial en la etapa del examen de la admisibilidad de las peticiones, le ha sido posible a la Comisión Interamericana evitar - y correctamente - el simple e inmediato rechazo de ciertas peticiones por no agotamiento de los ecursos internos. Le ha sido posible facilitar y gradualmente fortalecer aún más el acceso de los particulares lesionados a la instancia intemacional por medio de la aplicación de ciertas técnicas procesales, como las de la distribución de la carga de la prueba en relación con el agotamiento de los recursos internos y la del empleo de la presunción más favorable a los reclamantes resultante de la aplicación del critero de la ineficácia de los recursos internos.

La regla del agotamiento de los recursos internos da testimonio de la interacción entre el derecho internacional y el derecho interno y de la subsidiaridad - que le es implícita - del procedimiento internacional. Esta última no justificaría, sin embargo, una aplicación más rigurosa de la regla particularmente en la protección internacional de los derechos humanos. En la utilización de los recursos internos hay una complementaridad de derechos y deberes del reclamante y del reclamado: el elemento de reparación o resarcimiento de daños, al enfatizar la función y el esmero o perfeccionamiento de los tribunales nacionales en la administración de la justicia, es ciertamente más importante que el proceso formal o

Protection of Human Rights (At Global and Regional Levels)", 202 Recueil des Cours de l'Académie de Droit Intermational (1987), capítulo IX, pp. 243-299.

86 Cf., para un estudio general, A. A. Cançado Trindade, The Application of the Rule of Exhaustion of Local Remedies in Intemational Law, Cambridge, Cambridge University Press, 1983, pp. 6-56 y 290-322; A. A. Cançado Trindade, O Esgotamento de Recursos Intemos no Direito Intemacional, Brasilia, Editora Universidade de Brasília, 1984, pp. 111-177. 
mecánico de agotamiento de los recursos internos. ${ }^{87}$ Tal enfoque podrá conducir a una nueva caracterización de la naturaleza jurídica de la regla del agotamiento de los recursos internos en la protección internacional de los derechos humanos en los próximos años.

II. El Derecho de Petición o de Comunicación: El Enfoque del Sistema Interamericano (según la práctica anterior de la Comisión Interamericana de Derechos Humanos y según la Convención Americana sobre Derechos Humanos) de su Relación con Otros Procedimientos de Protección de los Derechos Humanos

1. Los Trabajos Preparatorios de la Convención Americana sobre Derechos Humanos: Su Coexistencia con Otros Instrumentos de Protección de los Derechos Humanos

Los redactores de la Convención Americana sobre Derechos Humanos se han beneficiado de la existencia anterior de otros tratados de derechos humanos tanto a nivel global (e.g., los Pactos de las Naciones Unidas sobre Derechos Humanos) como a nivel regional (e.g., la Convención Europea sobre Derechos Humanos); así, tuvieron ellos alguna base para la consideración de la cuestión de la coexistencia y coordinación de estos instrumentos de protección de los derechos humanos. Los trabajos preparatorios de la Convención Americana sobre Derechos Humanos se remontan a la Quinta Reunión de Consulta de Ministros de Relaciones Exteriores, que tuvo lugar en Santiago, en 1959; en aquella ocasión, paralelamente a la creación de la Comisión Interamericana de Derechos Humanos, la Quinta Reunión de Consulta también decidió encargar la elaboración de un proyecto de Convención regional sobre Derechos Humanos al Consejo Interamericano de Jurisconsultos. Este terminó su trabajo en 1959 (el así llamado "proyecto de Santiago"), llevando en consideración la historia legislativa, hasta entonces, de la Convención Europea y de los proyectos de Pactos de las Naciones Unidas sobre Derechos Humanos. 88

La Segunda Conferencia Especial Interamericana, que tuvo lugar en Rio de Janeiro en 1965, retomó la materia: envió al Consejo de la OEA el proyecto de Santiago de 1959 , juntamente con dos otros proyectos preparados por Uruguay y Chile, y los presentó a la Conferencia (para actualizar el proyecto preparado por el Conse jo Interamericano de Jurisconsultos), a fin de que el Consejo consultara a la Comisión Interamericana de Derechos Humanos, y a otros órganos y entidades que juzgara conveniente, sobre posibles enmiendas

87 A. A. Cançado Trindade, "Exhaustion of Local Remedies in Intemational Law and The Role of National Courts", 17 Archiv des Völkerrechts (1977-1978), pp. 333-370.

88 kCf., e.g., Karel Vasak, La Commission interaméricaine des droits de l'homme, Paris, LGDJ, 1968, pp. 175-187; Carlos Carcia Bauer, "La Observancia de los Derechos Humanos y la Estructuración del Sistema Intemacional de Protección en el Ambito Americano", La Convención Americana sobre Derechos Humanos, Washington, Secretaría General de la OEA, 1980, pp. 23-25. 
a los tres proyectos. La Comisión Interamericana los examinó en 1966 - 1967, y sometió un informe al Consejo de la OEA (y a su Comité de Asuntos Jurídicos y Políticos). Mientras tanto, a nivel global, la Asamblea General de las Naciones Unidas había adoptado los dos Pactos de las Naciones Unidas sobre Derechos Humanos (y Protocolo Facultativo) de 1966; frente a ello, y también al hecho de que el Protocolo de Reformas de la Carta de la OEA de 1967 (artículo 112) preveía la elaboración futura de una Convención Americana sobre Derechos Humanos, el Consejo de la OEA, de acuerdo con una recomendación de su Comité de Asuntos Jurídicos y Políticos, decidió consultar a los Estados miembros de la OEA sobre la cuestión en particular de la "posibilidad de coexistencia y de coordenación de las convenciones universales y regional" sobre la protección de los derechos humanos, de modo a "evitar el peligro de posibles conflictos de normas y de instituciones" a nivel global y regional.89 Mientras dos de las respuestas favorecían una única reglamentación sobre derechos humanos, a nivel global (i.e., los Pactos de las Naciones Unidas), para evitar duplicación y eventuales conflictos de competencia, ocho Estados sostuvieron, sin embargo, el punto de vista de que había la "posibilidad de coexistencia y coordinación de las convenciones globales y regional sobre derechos humanos".90

Como la mayoría de las respuestas (hasta fines de octubre de 1967) fueron favorables al proseguimiento de los trabajos de elaboración de una Convención Americana sobre Derechos Humanos, la Comisión Interamericana de Derechos Humanos, a su vez, decidió llevar a cabo un estudio comparativo de los proyectos ya elaborados y de los Pactos de las Naciones Unidas sobre Derechos Humanos (y Protocolo Facultativo). Tal estudio fué terminado el 4 de abril de 1968, y contenía una comparación detallada entre los dispositivos de los proyectos regionales (supra) y los de los Pactos de las Naciones Unidas sobre Derechos Humanos.91 Al afirmar la posibilidad de coexistencia entre los Pactos de las Naciones Unidas y una Convención regional (en el continente americano), este estudio recordó el ejemplo del Pacto de las Naciones Unidas sobre Derechos Civiles y Políticos; añadió, además, que, como el grado de protección real de los derechos humanos bajo los Pactos de las Naciones Unidas era "inferior" al de la Convención Europea, si, en el continente americano, simplemente se reemplazara el régimen existente en el sistema interamericano (cf. infra) por el de los Pactos de las Naciones Unidas, eso significaría un paso atrás

89 OEA / Conferencia Especializada Interamericana sobre Derechos Humanos, Anotación sobre el Proyecto de Convención Interamericana sobre Protección de Derechos Humanos, doc. OEA/Ser. KXVI/1.1 - doc. 12, del 22 de septiembre de 1969, pp. 1-2.

90 OEA / Relatório da Comissao de Assuntos Jurídico-Políticos acerca do Projeto de Convençao Interamericana sobre Direitos Humanos, doc. OEA/Ser. G/OV/C-i-8112/Rev. 2, del 24 de enero de 1968, pp. 1-2.

91 OEA / Comisión Interamericana de Derechos Humanos, Estudio Comparativo entre los Pactos de las Naciones Unidas sobre Derechos Civiles, Políticos, Económico, Sociales y Culturales y los Proyectos de Convención Interamericana sobre Derechos Humanos (relator, C.A. Dunshee de Abranches), doc. OEA/Serl. L/V/II.19 - doc. 18, del 4 de abril de 1968, pp. 1-51. 
en la protección internacional de los derechos humanos: la proyectada Convención Americana sería, así, necesaria.92 Además, ella debería no solamente ser complementaria a los Pactos de las Naciones Unidas y a otros instrumentos globales, sino también una convención regional "independiente", en el sentido de que debería contener su propia definición de los derechos garantizados y de sus propios procedimientos y mecanismos de protección. No debería ser necesario - concluyó el estudio - reproducir en el proyecto de Convención regional las definiciones contenidas en el Pacto de las Naciones Unidas sobre Derechos Económicos, Sociales y Culturales, ya que disposiciones correspondientes serían incorporadas a la Carta de la OEA a través de la ratificación del Protocolo de Reformas de 1967; las normas procesales e institucionales no entrarian en conflicto con las de los Pactos de las Naciones Unidas, puesto que estas últimas no creaban ni una Comisión ni una Corte del tipo, estructura y competencia previstas en el proyecto de Convención Americana.93

Una semana después (11 de abril de 1968), la Comisión Interamericana emitió una Opinión Consultiva en la cual juzgó "perfectamente posible" la coexistencia entre los Pactos de las Naciones Unidas (y Protocolo Facultativo) y la futura Convención Americana. La "necesidad y conveniencia" de una Convención Americana regional "autónoma" fue una respuesta a la "existencia de un Derecho Internacional Americano formado conforme a las necesidades específicas de los países del hemisferio" y resultó, además, de la "estrecha relación" que existía entre los derechos humanos y el desarrollo regional.94 Las disposiciones sustantivas del proyecto de Convención Americana podrían coincidir en algunos aspectos con aquellos del Pacto de las Naciones Unidas sobre Derechos Civiles y Políticos, con algunos "acrecentamientos necesários" requeridos por las "condiciones peculiares" del continente americano, pero no sería necesário incluir en la Convención Americana las definiciones de los derechos económicos, sociales y culturales contenidas en los respectivos Pactos de las Naciones Unidas, pues estas ya habían sido sustancialmente incorporadas al Protocolo de Reformas de la Carta de la OEA. Con respecto al mecanismo de protección, la Comisión Interamericana no previó "ningún conflicto" con los Pactos de las Naciones Unidas, pues los últimos no creaban una Comisión ni una Corte con la estructura y competencia previstas en el proyecto de Convención Americana. La Opinión Consultativa concluía destacando el "progreso" alcanzado por el proyecto de Convención regional al reafirmar el derecho de los individuos de presentar reclamaciones sobre violaciones de derechos huma-

Ibid., pp. 14-23, y cf. pp. 26-43 para un paralelo entre los derechos garantizados en los dos Pactos de las Naciones Unidas y los que haberían de ser garantizados en la proyectada Convención Americana.

93 Ibid., pp. 44-50.

94 OEA / Comisión Interamericana de Derechos Humanos, Dictamen: Estudio Comparativo entre los Pactos de las Naciones Unidas sobre Derechos Civiles, Políticos, Económico, Sociales y Culturales y los Proyectos de Convención Interamericana sobre Derechos Humanos, doc. OEA/Ser. L/V/II.19 - doc. 26, del 11 de abril de 1968, pp. 3-4. 
nos, mientras el Pacto de las Naciones Unidas sobre Derechos Civiles y Políticos adoptó el sistema opcional (contemplado en el Protocolo Facultativo). 95

El paso siguiente fué tomado por el Consejo de la OEA, que, en su resolución del 12 de junio de 1968, decidió solicitar a la Comisión Interamericana que preparase una versión revisada y completa del "Proyecto de Convención Americana sobre Derechos Humanos" "en armonía" con los Pactos de las Naciones Unidas sobre Derechos Humanos 96 - que sería sometida a los Gobiemos para sus comentarios; tales observaciones y enmiendas preliminares de los Gobiemos serían despues sometidas a una Conferencia Interamericana Especializada, que sería convocada para decidir sobre la aprobación y la apertura a la firma de una Convención regional sobre Derechos Humanos. El proyecto revisado fué inmediatamente preparado por la Comisión Interamericana en julio de 1968; las propuestas de artículos contenían comentarios que esbozaban un paralelo con las disposiciones correspondientes en los Pactos de las Naciones Unidas sobre Derechos Humanos (principalmente el Pacto sobre Derechos Civiles y Políticos) y también con algunas disposiciones de la Convención Europea sobre Derechos Humanos. 97

En relación con el mecanismo de protección, el proyecto revisado de la Comisión llevó en consideración la experiencia bajo la Convención Europea (e.g., en la creación - paralela a la Comisión - también en el marco de la Convención Americana, de una Corte). Estableció también el sistema periódico de informes (art. 41) y, en relación con el sistema de peticiones, recordó el funcionamiento "por más de ocho años" del régimen de peticiones individuales ante la Comisión Interamericana; este sistema, de acuerdo con la Comisión, debería ser mantenido en la futura Convención, por lo que sólo excepcionalmente, en casos de violaciones graves y reiteradas de derechos humanos, serían presentadas reclamaciones interestatales ante la Comisión. Significativamente, en su proyecto revisado, la Comisón omitió la referencia a la "denegación de justicia" - una expresión que aparecía en los

95 Ibid., pp. 4-5. Los Informes sobre el trabajo realizado durante sesiones sucesivas de la Comisión Interamericana de Derechos Humanos revelan una preocupación constante, durante los trabajos preparatorios de la Convención Americana, en garantizar su coordinación adecuada con los Pactos de las Naciones Unidas (CIDH, Report... XVIIth Session, 1967, p. 3; CIDH, Report... XIXth Session, 1968, pp. 12-13), llevando en consideración la experiencia de las Naciones Unidas en la elaboración de los Pactos, como también la experiencia de los Estados europeos con la Convención Europea de Derechos Humanos de 1950 (CIDH, Report... XVth Session, 1967, pp. 11 y 19-20; CIDH, Report.. XIVth Session, 1966, pp. 18-19; CIDH, Report... XIIIth Session, 1966, pp. 6 y 35). La Comisión Interamericana, a su vez, prestó atención a una propuesta (de 1967) de la Comisión de Derechos Humanos de las Naciones Unidas (cf. CIDH, Report... XXth Session, 1968, pp. 34-37) y, anteriormente, a la experiencia de las "comisiones intemacionales que actúan en el campo de los derechos humanos" (cf. CIDH, Report... IXth Session, 1964, p. 30).

96 OEA, Anotación..., doc. cit., supra n. 89, p. 4.

97 Ibid., pp. 4-38. 
proyectos anteriores (supra) - "en vista de su caracter polémico, que podría hacer difícil la ratificación de la Convención"98.

Los trabajos preparatorios de la Convención Americana alcanzaban así su etapa final. Algunas de las observaciones sometidas por los Gobiemos sobre el proyecto revisado de la Comisión contenían referencias a disposiciones correspondientes del Pacto de las Naciones Unidas sobre Derechos Civiles y Políticos 99 y de la Convención Europea sobre Derechos Humanos 100. La Organización Internacional del Trabajo también envió sus comentarios sobre el proyecto revisado de la Comisión Interamericana, frente al hecho de que trataba de cuestiones que habían sido objeto de las Convenciones de la OIT, ratificadas por un número considerable de Estados del continente americano, pero que contenían ciertas diferencias con respecto a las disposiciones correspondientes de ciertas Convenciones de la OIT. La OIT tomó conocimiento del proyecto de artículo 27101, en el cual ninguna disposición de la Convención Americana debería ser interpretada como si derogase o limitase cualquier derecho o libertad reconocidos en virtud de otra Convención en la cual uno de los Estados Partes en la Convención Americana sea también Parte: la OIT, sin embargo, sometió sus comentarios con el objetivo de "evitar cualquier conflicto entre las normas de carácter regional y las normas de la OIT sobre la materia"102. Sus observaciones se concentraron, sin embargo, en algunas normas sustantivas 103 (más que en los mecanismos de implementación).

Durante la Conferencia Especializada Interamericana sobre Derechos Humanos, que tuvo lugar en San José de Costa Rica, en noviembre de 1969, dos Comisiones de trabajo estudiaron, respectivamente, las partes sustantivas y proccesales del proyecto de Convención; aunque la Acta Final de la Conferencia no hace cualquier referencia explícita al problema en

98 Ibid., pp. $41-42$ y $45-51$.

99 Cf., e.g., las observaciones de Argentina, doc. OEA/Ser. K/XVI/1.1 - doc. 8, del 26 de septiembre de 1969, pp. 4-5; de Estados Unidos, doc. OEA/Ser. K/XVI/1.1 - doc. 10, del 5 de octubre de 1969, pp. 8-9, 13 y 18; de Chile, doc. OEA/Ser. K/XVI/1.1 - doc. 7, del 26 de septiembre de 1969, pp. 1,3 y 5-6, y cf. pp. 8 y 6 con referencia también al Pacto de las Naciones Unidas sobre Derechos Económicos, Sociales y Culturales.

100 Cf., e.g., las observaciones del Brasil, doc. OEA/Ser. K/XVI/1.1 - doc. 31, del 11 de noviembre de 1969, p. 3; de Estados Unidos, doc. cit., supra n. 99, pp. 9 y 32; de Chile, doc. cit., supra n. 99, p. 10.

101 Que se ha transformado en el artículo 29 (b) de la Convención Americana sobre Derechos Humanos.

102 OEA / Conferencia Especializada Interamericana sobre Derechos Humanos, Comentarios de la Oficina Intemacional del Trabajo al Proyecto de Convención Interamericana sobre Derechos Humanos, doc. OEA/Ser. K/XVI/1.1 - doc. 14, de 17 de octubre de 1969, p. 1.

103 Es decir, el proyecto de art. 5 (3) y las disposiciones correspondientes de la Convención $n^{2} 29$ de la OIT (sobre Trabajo Forzado - art. 2 (2)); proyecto de art. 15 y la Convención $n^{2} 87$ de la OIT (sobre Libertad de Asociación y Protección del Derecho de Organizarse); ibid., pp. 1-4. 
examen ${ }^{104}$, quedó claro, como revela el precedente estudio de los trabajos preparatorios que llevaron a la firma de la Convención Americana sobre Derechos Humanos, en noviembre de 1969, que sus redactores mantuvieron durante las diferentes etapas de su trabajo la conciencia de la necesidad de coordinación de los distintos instrumentos de derechos humanos a nivel global y regional, sin perjuicio de la expresión regional de la protección de los derechos humanos en el continente americano.

\section{El Derecho de Petición o Comunicación Individual en el Sistema Interamericano de Protección: El Enfoque de su Relación con Otros Procedimientos, con Anterio- ridad a la Convención Americana sobre Derechos Humanos}

Ya se hizo referencia al hecho de que, tanto en los antecedentes como en el desarrollo inicial del sistema interamericano de protección de los derechos humanos, hubo una mezcla de instrumentos obligatorios y recomendatorios, muchos de los cuales referentes a aspectos de la protección de derechos individuales en el continente americano.105 Aún actualmente, subsiste una dualidad de regímenes. El primero se aplica al caso de Estados Partes en la Convención Americana sobre Derechos Humanos de 1969, con base en la propia Convención; el segundo, al de los Estados no Partes en la Convención, con base en la Carte de la OEA, la práctica anterior de la Comisión Interamericana de Derechos Humanos y la Declaración Americana de Derechos y Deberes del Hombre de 1948. Un ejemplo de la mezcla de instrumentos recomendatorios y obligatorios en la elaboración del sistema regional interamericano de protección es la propia creación, en 1959, de la Comisión Interamericana de Derechos Humanos (anterior, por lo tanto, a la Convención Americana) a través de una resolución, y no de un tratado. 106

La experiencia de la Comisión Interamericana con respecto al examen de comunicaciones sobre supuestas violaciones de derechos humanos presenta singularidades (e.g., en cuanto a la aplicación de la regla del agotamiento de los recursos internos ${ }^{107}$ ) e indicaciones para el estudio de la relación del derecho de petición o de comunicación bajo el sistema interamericano de protección con otros procedimientos congéneres. En efecto, los antiguos Estatuto y Reglamento de la Comisión Interamericana, como también su práctica hasta fines de la década de 1970, permiten sugerir que la naturaleza de las comunicaciones o peticiones puede tener influencia en la cuestión de su coexistencia y coordinación con aquellas (comunicaciones o peticiones) bajo otros procedimientos. El antiguo Estatuto de la Comi-

104 Cf. OEA, Conferencia Especializada Interamericana sobre Derechos Humanos - Acta Final (San José, 1969), doc. OEA/Ser. C/VI/18.1, Washington, Secretaría General de la OEA, 1970, pp. 1-13.

105 Cf. A. A. Cançado Trindade, op. cit. supra n. 82, pp. 498-499.

106 Cf. ibid., pp. 499-505.

107 Cf. Parte I, supra. 
sión (vigente hasta 1979) hacía referencia a comunicaciones para la recolección de "informaciones consideradas pertinentes por la Comisión" que servirían de base para sus "recomendaciones" solamente (art. 9 (bis)). El antiguo Reglamento de la Comisión (vigente hasta 1980) preveía dos tipos de procedimientos: un procedimiento ordinario (arts. 37-52), en el cual el examen de comunicaciones por la Comisión podría llevar a la adopción de recomendaciones (como bajo el Estatuto, supra) y a la preparación de informes, y un procedimiento especial (arts. 53-57), en el cual reclamaciones de violaciones de ciertos derechos (la mayoría derivados de la Declaración Americana de Derechos y Deberes del Hombre, art. 53) podrían ser examinadas por sus propios méritos.

El procedimiento ordinario se limitaba a verificar, como una de las condiciones de admisibilidad de las comunicaciones, que éstas no fueran "sustancialmente las mismas" que otras comunicaciones anteriormente examinadas por la propia Comisión (art. 39 (b)), pero no contenía ninguna cláusula de la coordinación con otros procedimientos coexistentes, aunque fuera concebido para permitir el examen de las comunicaciones en cuanto al mérito, lo que puede haber sido sorprendente para algunos. 108 Evidentemente, eso permitió a la Comisión proceder con toda flexibilidad al tratar de las comunicaciones en relación con otros procedimientos coexistentes. La práctica de la Comisión Interamericana bajo los antiguos Estatuto y Reglamento y en el período anterior a la entrada en vigor (en 1978) de la Convención Americana sobre Derechos Humanos de 1969 presenta algunas ilustraciones pertinentes.

\section{El Derecho de Petición o Comunicación Individual en el Sistema Interamericano y Otros Procedimientos: La Práctica Inicial de la Comisión Interamericana de Derechos Humanos}

La colección de Reports on the Work Accomplished by the Inter-American Commission on Human Rights en sus sucesivas sesiones 109 contiene algunas decisiones de la Comisión que tienen una influencia directa sobre la cuestión de la coordinación de los distintos mecanismos (de petición) para la protección internacional de los derechos humanos, o que, por lo menos, revelan el enforque inicial de la Comisión sobre la materia. Así, al considerar la

108 Cf., a ese respecto, M.E. Tardu, "The Protocol to the United Nations Covenant of Civil and Political Rights and the Inter-American System: A Study of Co-Existing Petition Procedures", 70 American Joumal of Intemational Law (1976, pp. 782-783; A. A. Cançado Trindade, "CoExistence and Co-ordination of Mechanisms of Intemational Protection of Human Rights (At Global and Regional Levels)", 202 Recueil des Cours de l'Académie de Droit Intemational (1987), pp. 190-209.

109 Publicado regularmente hasta 1975, cuando fue interrumpido; desde entonces los documentos que solían aparecer en esa colección fueron incorporados a los Informes Anuales de la Comisión Interamericana. 
comunicación n⿳⺈ 1738, concerniente a Chile, denunciando la detención arbitraria y tortura sufrida por un abogado chileno (Y. O. Bulnes), la Comisión Interamericana descubrió que los reclamantes habían anteriormente presentado "la misma reclamación" a la Comisión de Derechos Humanos de las Naciones Unidas, pero no obstante decidió que "esta circunstancia no excluía su propia competencia", aunque le pareciese "deseable determinar el estado del caso en las Naciones Unidas".110 En la consideración de la comunicación n 1749, concerniente a Colombia, denunciando acciones gubernamentales que supuestamente violaban el derecho de libertad sindical, la objeción del Gobierno colombiano de que las reclamaciones en cuestión habían sido presentadas por los sindicatos interesados "a la OIT y a la CIDH a la vez" no impidió a la Comisión Interamericana examinar la materia; ella decidió al final que los actos denunciados "no tenían relación con una desconsideración de la libertad sindical por el Gobierno de Colombia".111

En otra ocasión, la Comisión Interamericana consideró la comunicación n 1734 (Cuba) incompatible con las disposiciones de su Estatuto, "sin perjuicio de enviar el caso a la Cruz Roja Internacional para que pudiera buscar una solución".112 En el examen de las comunicaciones nº 1687 y 1699 (Nicaragua), la Comisión aprobó la recomendación del relator de que los casos fuesen enviados para la Oficina Regional del Alto Comisionado de las Naciones Unidas para Refugiados en América Latina "para que fuese buscada una solución favorable a las partes interesadas". 113 La Comisión examinó las comunicaciones nº 1526 y 1545 (República Dominicana) con base en informaciones suministradas por la Oficina del Alto Comisionado de las Naciones Unidas para Refugiados. 114 Con respecto a la comunicación $n^{0}$ 1677, a pesar de la objeción del Gobiemo de Haití de que los hechos en cuestión habían sido denunciados tanto en las Naciones Unidas como en la OEA y "nada" había sido hecho "acerca de ellos", la Comisión Interamericana prosiguió con el examen de la recla-

$110 \mathrm{CIDH}$, Report on the Work Accomplished by the Inter-American Commission on Human Rights During Its Twenty-Ninth Session, 1972, doc. OEA/Ser. L/V/II.29 - doc. 40, Rev. 1, de 1972, p. 7; y cf. CIDH, Report on the Work Accomplished by the IACHR During Its Thirtieth Session, 1972, doc. OEA/Ser. L/V/II.30 - doc. 45, Rev. 1, de 1973, p. 37; CIDH, Report on the Work Accomplished by the IACHR During Its Thirty-First Session, 1973, OEA/Ser. L/V/II.34 - doc. 54, Rev. 1, de 1974, p. 42.

111 CIDH, Report on the Work Accomplished by the IACHR During Its Thirieth Session, 1973, doc. OEA/Ser. L/V/II.30 - doc. 45, Rev. 1, de 1973, p. 24, y cf. pp. 65-66.

$112 \mathrm{CIDH}$, Report on the Work Accomplished by the IACHR During Its Twenty-Sixth Session, 1971, doc. OEA/Ser. L/V/II.26 - doc. 37, Rev. 1, de 1972, p. 12.

$113 \mathrm{CIDH}$, Report on the Work Accomplished by the IACHR During Its Twenty-Sixth Session, 1971, doc. OEA/Ser. L/V/II.26 - doc. 37, Rev. 1, de 1972, pp. 36-38; y cf. CIDH, Report on the Work Accomplished by the IACHR During Its Twenty-Fifth Session, 1971, doc. OEA/Ser. L/V/II.25 doc. 41, Rev., de 1971, pp. 16 y 35.

$114 \mathrm{CIDH}$, Report on the Work Accomplished by the IACHR During Its Twenty-Sixth Session, 1971, doc. OEA/Ser. L/V/II.26 - doc. 37, Rev. 1, de 1972, p. 40. 
mación. ${ }^{115}$ Otros ejemplos pertinentes podrían ser citados. La comunicación $\mathrm{n}^{2} 1925$, presentada a la Comisión el 14 de abril de 1975, denunciaba la detención de trabajadores en Bolivia y requería la intervención de la Comisión Interamericana para asegurar la restitución de derechos civiles y políticos en ese país como también la observancia de las Convenciones de la OIT vigentes. 116 Otra comunicación, fechada del 6 de marzo de 1969, solicitando ayuda para las comunidades judías en Egipto, Siria e Irak, presentada curiosamente a la Comisión Interamericana, fué enviada por ésta a la Comisión de Derechos Humanos de las Naciones Unidas y al Alto Comisionado de las Naciones Unidas para Refugiados.117

La Comisión no se sintió inhibida de llevar a cabo las medidas descritas arriba. Hubo una época - especialmente en la consideración de las comunicaciones $n^{\circ} s 1738$ (Chile) y 1749 (Colombia) (supra) - en que la cuestión de la admisibilidad de comunicaciones presentadas a la Comisión Interamericana y que hubiesen también sido sometidas a algún otro organismo intemacional provocaba algún debate entre los miembros de la Comisión (en 1973); les pareció que tal circunstancia no excluía la competencia de la Comisión (de acuerdo con su Estatuto y Reglamento), sin perjuicio de las medidas de averiguación tomadas por otros organismos (de las Naciones Unidas). 118

\section{El Ejercicio de Funciones Duales o Paralelas dentro del Mismo Sistema Regional de Protección}

Los ejemplos arriba mencionados fueron tomados de la práctica de la Comisión anterior a la entrada en vigor de la Convención Americana sobre Derechos Humanos, en 1978. La preocupación de la Comisión, en ese entonces y subsecuentemente, de asegurar el respeto a los derechos humanos en los Estados miembros de la OEA, independientemente de la ratificación de la Convención Americana, se hace evidente con la inclusión, en los Informes Anuales de la Comisión, de una sección que trae informaciones suministradas por los gobiemos de los Estados miembros de la OEA sobre el "Progreso en la Realización de los

$115 \mathrm{CIDH}$, Report on the Work Accomplished by the IACHR During Its Twenty-Fifth Session, 1971, doc. OEA/Ser. L/V/VII.25 - doc. 41, Rev., de 1971, pp. 31-32.

116 CIDH, Informe sobre la Labor Desarrollada por la C.I.D.H. en Su Trigésimo-Quinto Período de Sesiones, 1975, doc. OEA/Ser. L/V/II.35 - doc. 45, Rev. 1, de 1975, pp. 8-9.

117 CIDH, Report on the Work Accomplished by the IACHR During Its Twenty-First Session, 1969, doc. OEA/Ser. L/V/VII.21 - doc. 27, de 1970, pp. 16-17.

$118 \mathrm{CIDH}$, Report on the Work Accomplished by the Inter-American Commission on Human Rights at Its Thirtieth Sesseion, 1973, doc. OEA/Ser. L/V/II.30 - doc. 45, Rev. 1, de 1973, p. 65. Los miembros de la Comisión examinaron, por ejemplo, la cuestión de comunicaciones que alegaban violaciones de ciertos derechos humanos en la Declaración Americana que contenían reclamaciones que habían sido sometidas a otros organismos intemacionales, en particular la OIT, referentes a "violaciones de la libertad sindical" (en el continente americano); les pareció apropriado elaborar un documento sobre ese asunto (cf. ibid., pp. 65-66). 
Objetivos Establecidos en la Declaración Americana de Derechos y Deberes del Hombre", de 1948.119 Además, ha habido ocasiones en que la Comisión Interamericana instó a los Estados miembros de la OEA a que incorporaran en los textos de sus Constituciones ciertas categorías de derechos (e.g., en cuestiones laborales) y a que "armonizaran sus respectivas legislaciones con las disposiciones de convenciones y recomendaciones de la Organización Intemacional del Trabajo".120 Tales ejemplos de la preocupación de la Comisión de asegurar la observancia de los derechos humanos en los Estados miembros de la OEA independientemente de la ratificación de la Convención Americana es sólo un aspecto de la materia; enfocado el problema desde el punto de vista de los Estados, es seguro que sus ratificaciones de los tratados de derechos humanos tales como la Convención Americana constituyen condición sine qua non para que traten con seriedad de la cuestión de la protección de los derechos humanos tanto a nivel intemacional (regional) como a nivel nacional.121

Con la consolidación del sistema regional de protección (entrada en vigor de la Convención Americana) 122 , es importante llevar en consideración el ejercicio de funciones, por la Comisión Interamericana, con relación a los "Estados Partes" en la Convención así como a los "Estados miembros" de la OEA, para comprender el contenido pertinente del nuevo Estatuto (de 1979) y del nuevo Reglamento (de 1980) de la Comisión, que tendrían precisamente que incluir las obligaciones de dicho organismo frente a los Estados miembros de la OEA o a los Estados Partes en la Convención Americana123 (infra). Efectivamente, luego de la entrada en vigor, en 1978, de la Convención Americana, la antigua distinción entre los procedimientos ordinarios y especiales para el examen de comunicaciones desapa-

119 Generalmente relacionadas a medidas legislativas, decisiones judiciales y otras medidas (e.g., actos administrativos) a nivel nacional. Cf. Relatório Anual da CIDH - 1977, doc. OEA/Ser. L/V/II.47 doc. 13, Rev. 1, de 1979, pp. 13-21; Relatório Anual da CIDH - 1979/1980; doc OEA/Ser. L/V/II.50 - doc. 13, Rev. 1, de 1980, pp. 77-84 (este último Informe es el único a referirse no sólo a la Declaración Americana de 1948 sino también a la Convención Americana sobre Derechos Humanos).

120 Annual Report of the Inter-American Commission on Human Rights, 1971/1972, doc. OEA/Ser. L/V/II.29 - doc. 41, Rev. 2, de 1973, p. 33.

121 A. A. Cançado Trindade, "A Evoluçao das Competências dos Orgaos Políticos Intemacionais: Os Casos da Organizaçao das Naçoes Unidas e da Organizaçao dos Estados Americanos", 28 Revista Brasileira de Política Intemacional (1985), $\mathrm{n}^{\mathrm{Q}}$ 109-110, p. 132.

122 Cf. A. A. Cançado Trindade, op. cit. supra n. 82, pp. 505-514.

123 Informe Anual de la Comisión Interamericana de Derechos Humanos, 1979/1980, doc. OEA/Ser. L/V/II.50 - doc. 13, Rev. 1, de 1980, pp. 9-13. El propio Consejo de la OEA, en una resolución adoptada por consenso, confirmó que la Comisión aplicaría la Convención a los Estados Partes, y su Estatuto y Reglamento (en vigor en aquel momento) y la Declaración Americana de Derechos Humanos (de 1948) a los Estados que no fuesen Partes en la Convención; E. Vargas Carreño, "[Derechos Humanos:] El Perfeccionamento de los Mecanismos Interamericanos a la Luz de su Experiencia", Estudios Intemacionales: Derechos Humanos y Relaciones Intemacionales (ed. W. Sánches G.), Santiago, Instituto de Estudios Intemacionales, 1979, pp. 223. 
reció en el nuevo Estatuto de la Comisión (aprobado por la Novena Asamblea General de la OEA, en 1979) y en el nuevo Reglamento (aprobado por la Comisión en 1980 y modificado en 1985). Pero una nueva distinción fué introducida: el nuevo Estatuto especificó los poderes de la Comisión en relación con los Estados miembros (art. 18) que son Partes en la Convención Americana (art. 19) y con los que no son Partes en la Convención (art. 20). Con respecto a los Estados no Partes en la Convención, los poderes emanan de la propia Carta de la OEA y la Práctica anterior de la Comisión, que debería seguir aplicando la Declaración Americana de Derechos y Deberes del Hombre de 1948; en paralelo, la práctica aplicable a los Estados Partes en la Convención deriva de ese instrumento.124 El nuevo Reglamento de la Comisión, a su vez, prevé el examen de peticiones o comunicaciones relacionadas tanto con los Estados Partes (arts. 31-50) como con los Estados no-Partes (arts. 51-54) en la Convención Americana, con base en la Convención Americana y en la Declaración Americana, respectivamente. El nuevo Reglamento tiene disposiciones de aplicación común a todas las peticiones (disposiciones generales de los artículos 26, 27 y 30 , y artículos 32 hasta 43, al cual se refiere expresamente el artículo 52). Actualmente, por lo tanto, dentro del mismo sistema regional interamericano de protección de los derechos humanos, hay una "coexistencia" de disposiciones (supra) dirigidas a los Estados miembros de la OEA que son Partes y a aquellos que no son Partes en la Convención Americana sobre Derechos Humanos.

\section{El Derecho de Petición o Comunicación: El Enforque de la Convención Americana sobre Derechos Humanos de su Relación con Otros Procedimientos}

En relación con otros sistemas de protección de derechos humanos, la Convención Americana prevé que la admisión por la Comisión Interamericana de una petición o comunicación (presentada de acuerdo con los artículos 44 o 45 de la Convención) estará sujeta, inter alia, a la exigencia de que la materia de la petición o de la comunicación "no esté pendiente" en otro procedimiento internacional de solución (art. 46 (1) (c)). Además, la Comisión deberá considerar inadmisible cualquier petición o comunicación si ella, inter alia, "es sustancialmente la misma" que otra previamente examinada por la Comisión o por otra organización internacional (art. 47 (b)). Estas disposiciones son complementadas por el artículo 39, sobre "duplicación de procedimientos", del nuevo Reglamento de la Comisión (aprobado en 1980 y modificado en 1985).125 De acuerdo con el artículo 39, aplicable a todas las peticiones (cf. supra), la Comisión (párrafo 1) "no considerará" una petición en el caso en que la mate-

124 Cf. OEA, Annual Report of the Inter-American Commission on Human Rights, 1978/1980, doc. OEA/Ser. L/V/II.50 - doc. 13, Rev. 1, de 1980, p. 11.

125 El artículo 39 del Reglamento actual de la Comisión retoma, sin modificación, el antiguo artículo 36 introducido en el Reglamento de la Comisión aprobado en 1980, anteriormente a las modificaciones de 1985. 
ria de la misma "se encuentre pendiente de otro procedimiento de arreglo ante una organización internacional gubernamental de que sea parte el Estado aludido", o de que "sea sustancialmente la reproducción de una petición pendiente o ya examinada y resuelta por la Comisión u otro organismo internacional gubernamental de que sea parte el Estado aludido".

El artículo 39 añade (párrafo 2), sin embargo, que la Comisión "no se inhibirá de conocer y examinar" una petición en los casos arriba (párrafo 1) previstos cuando:

"(a). el procedimiento seguido ante la otra organización u organismo se limite al examen de la situación general sobre derechos humanos en el Estado aludido, y no exista una decisión sobre los hechos específicos que son objeto de la petición sometida a la Comisión o que no conduzca a un arreglo efectivo de la violación denunciada;

(b). el peticionario ante la Comisión o algún familiar sea la presunta víctima de la violación denunciada y el peticionario ante dichas organizaciones sea una tercera persona o una entidad no gubernamental, sin mandato de los primeros."

La Comisión, desde la entrada en vigor de la Convención Americana en 1978 y la aprobación de su nuevo Reglamento en 1980 (modificado en 1985), ha podido, así, apoyarse en indicaciones expresas de cómo proceder en casos de "duplicación de procedimientos", diferentemente de lo que sucedía anteriormente, cuando la ausencia de una tal cláusula de coordinación (cf. supra) le permitió una libertad y una flexibilidad considerables en el tratamiente de comunicaciones en relación con otros procedimientos coexistentes. Sin embargo, esas indicaciones no parecen haber tenido, hasta hoy, muchas consecuencias prácticas. En efecto, los últimos Informes Anuales de la Comisión - de 1980 hasta el presente126 - no traen elementos que aclaren la aplicación real de las disposiciones arriba mencionadas; contienen apenas algunas indicaciones relativas a la cuestión de la coordinación de disposiciones a un nivel normativo, más bien que procesal.127. Eso no significa

126 I.e., los Informes Anuales de la Comisión de 1980-1981, 1982-1983, 1983-1984 y 1984-1985, publicados hasta el momento.

127 El examen, por la Comisión, del Caso 2141 (Estados Unidos), en 1981, puso en evidencia la cuestión de coordinación pero a nivel nomativo, entre la formulación del derecho a la vida a nivel regional (interamericano) y a nivel global (Pacto de las Naciones Unidas sobre Derechos Civiles y Políticos, art. 6 (1)). Cf. OEA, Informe Anual de la Comisión Interamericana de Derechos Humanos, 1980-1981, doc. OEA/Ser. L/VL!!.54 - doc. 9, Rev. 1, de 1981, p. 46. Del mismo modo, el examen por la Comisión del Caso 2711 (Uruguay), en 1983, hacía referencia al derecho a la libertad de movimiento y residencia como concebido en la Declaración Americana de Derechos y Deberes del Hombre (art. VIII) y en la Declaración Universal de Derechos Humanos (art. 13). Cf. OEA, Informe Anual de la Comisión Interamericana de Derechos Humanos, 1982-1983, OEA/Ser. L/V/II.61 - doc. 22, Rev. 1, de 1983, p. 143. Los casos relatados en el último Informe Anual de la Comisión Interamericana denotan mucha atención a la cuestión del agotamiento de recursos internos, más bien que a la cuestión del recurso a mecanismos intemacionales coexistentes. Cf. OEA, 
que, en el futuro, las disposiciones mencionadas no puedan asegurar algun grado de coordinación con procedimientos coexistentes, probablemente de manera similar a la interpretación y aplicación del artículo 5 (2) (a) del Protocolo Facultativo del Pacto de las Naciones Unidas sobre Derechos Civiles y Políticos por el Comité de Derechos Humanos. 128

Hasta el presente, la cuestión ha sido suscitada con respecto a un Estado miembro de la OEA que es también Parte en el Pacto y el Protocolo Facultativo (Uruguay): en los casos en que fué planteada, la Comisión Interamericana procedió normalmente con su examen, hasta el momento en que los reclamantes requirieron la retirada de los casos de la consideración de la Comisión Interamericana, para que pudieran ser planteados ante el Comité de Derechos Humanos. La Comisión Interamericana, por lo tanto, en tales casos, ha concordado con el deseo de los reclamantes (preferencia por el nivel global - Naciones Unidas), en un ejemplo de la aplicación del criterio de la libertad de elección de los reclamantes, las supuestas víctimas. 129

Es significativo que el artículo 39 (2) del nuevo Reglamento de la Comisión Interamericana (supra) establezca limitaciones precisas en cuanto al impedimento de la consideración de una petición pendente lite, o sea: ratione materiae, si el otro procedimiento coexistente empleado se refiere a una situación general sobre derechos humanos y no hay decisión sobre los hechos específicos alegados en la petición (individual) en cuestión, o es uno que no llevará a una solución ef ectiva de la violación denunciada; ratione personae, si el reclamante en el otro procedimiento coexistente empleado es una "tercera parte" o una entidad no-gubernamental que no tiene mandato del reclamante ante la Comisión Interamericana. En tales casos la Comisión Interamericana no se abstendría de recibir y examinar la petición.

La primera salvaguardia arriba mencionada garantizaría la operación normal de un procedimiento como el del sistema de la resolución normal de un procedimiento como el del sistema de la resolución 1503 del ECOSOC130, paralelo al de la Comisión Interamericana. La segunda salvaguardia está de acuerdo con la opinión, también compartida a nivel global, de que "la misma materia" (una expresión encontrada en el artículo 5 (2) (a) del Protocolo Facultativo del Pacto de las Naciones Unidas sobre Derechos Civiles y Políticos) debe ser considerada como significando y cubriendo también las mismas partes en el caso, y no una "tercera parte no relacionada". Esta salvaguardia, además de hacer posible y probable un paralelismo uniforme en las prácticas del Comité de Derechos Humanos y de la Comisión

Inforne Anual de la Comisión Interamericana de Derechos Humanos, 1985-1986, doc. OEA/Ser. L/V/II.68 - doc. 8, Rev. 1, de 1986, pp. 39-134.

128 Cf. A. A. Cançado Trindade, op. cit. supra n. 108, capítulo V, pp. 127-145.

129 Cf. ibid., capítulo IV, pp. 113-126.

130 Cf. ibid., capítulo IX, pp. 210-228. 
Interamericana sobre la materia, también satisface a los intereses procesales - o al menos corresponde a las expectativas legítimas - de los reclamantes, las supuestas víctimas.

En conclusión, en las últimas décadas hemos testimoniado la gradual expansión de la protección intemacional de los derechos humanos y la correspondiente consolidación de los instrumentos de protección. Tales instrumentos son claramente orientados hacia la salvaguardia de las víctimas. Se ha logrado el fortalecimiento y el perfeccionamiento de los mecanismos de protección en gran parte gracias al tratamiento adecuado de cuestiones de operación de dichos mecanismos tales como las examinadas en el presente estudio (a saber, la del agotamiento de los recursos intemos, y la de la relación y coordinación de sistemas de petición o comunicación bajo procedimientos distintos). Es importante que técnicas procesales y presunciones sigan siendo aplicadas en favor de las presumidas víctimas, con miras en última análise a la fiel y plena realización del objeto y propósito de los instrumentos de protección del ser humano. 
state only because of Great Britain's colonial politics, and that Kuwait has always been an integral part of Iraq. Therefore, this article discusses the historical and legal aspects which were brought forward by Saddam Hussein in order to legitimize the invasion and the attempt to incorporate Kuwait into Iraq. Three questions are crucial in this respect:

1. Was Kuwait an integral part of the Ottoman province of Basra?

2. Are there any legitimate claims of Iraq, as a successor state of the Ottoman Empire, to Kuwait?

3. How has Iraq sustained its claims in the past?

The answers to these questions show that Iraqi claims to Kuwait are unfounded.

\section{On the Court System in Libya}

\section{By Hans-Georg Ebert}

As the legal system of Libya is often analysed on the occasion of spectacular or doubtful practices in the judiciary, often with a political background, the institutional structure of the court system itself and its legal basis is seldomly described on a plain legal basis. The article describes the institutional structure in which the courts, attomeys-at-law and court administration work. The article tries to concentrate on the valid statutes and to give an overview, although frequent changes and the dichotomy of state law and sharia make a brief and clear description either impossible or incomplete.

The author also introduces the valid principles governing the legal procedure at court and explains the extent to which the govemment did and does interfere - disrespecting the independence of the judiciary. He concludes that the present Libyan court system is the result of a dual strategy, an attempt to reorganize the legal system integrating the traditional Islamic legal practices and institutions.

\section{Selected Issues Concerning the Operation of Inter-American System for the Protec- tion of Human Rights}

\section{By Antônio Augusto Cançado Trindade}

In the operation of the inter-American system of human rights protection, two issues deserve special attention: the exhaustion of local remedies as a condition of admissibility of 
human rights communications and the relationship of the right of petition or communication in the inter-American system with other human rights petitioning systems.

As the first question, the local remedies rule has been applied with flexibility in the interAmerican system pursuant to its rationale in the domain of international human rights protection, endowed with a specificity of its own. By means of procedural techniques in a diversity of solutions, presumptions have been made to operate in favour of the alleged victims. Without detracting from generally recognized rules of international law, the local remedies rule has received a particularly flexible application in the inter-American system of human rights protection (contrasting, e.g., with its more rigid application in discretionary diplomatic protection), disclosing the interaction between international law and domestic law and stressing the importance of the element of local redress in the international legal procedure.

As to the second question, there was been an evolution from the initial absence of a clause of co-ordination between petitioning systems to the provision of express indications or guidelines to achieve that co-ordination, without detriment to the complainants and to the necessities of protection. This has contributed to the enhancement of the procedural position of the alleged victims. It is important and necessary that techniques and presumptions keep on being applied in a way to redress the balance in favour of the alleged victims, pursuant to the ultimate object and purpose of human rights instruments, which are fundamentally victim-oriented.

The New Montreal Protocol: A Small Step for the Protection of the Ozone Layer, a Big Step for International Law and Relations

\section{By Hermann Ott}

In June, 1990, the parties to the Montreal Protocol on Substances that Deplete the Ozone Layer met in London to negotiate and adopt an amendment which is remarkable in many ways and may very well open a new chapter in international relations. It was agreed upon to phase out completely the production and consumption of a whole range of chemical substances which are known to destroy the ozone layer. In addition, the parties reached an unprecedented agreement on a financial mechanism with as of yet unforseeable consequences for North-South relations, for the international economic order and for international law. This financial mechanism will be funded by the industrialized states and is designed to enable developing countries to restructure their industries in order to avoid ozone-depleting substances. Thus the conference may have set an important precedent in the fight against global environmental deterioration and may prove to be a step towards a genuinely sustainable development. 